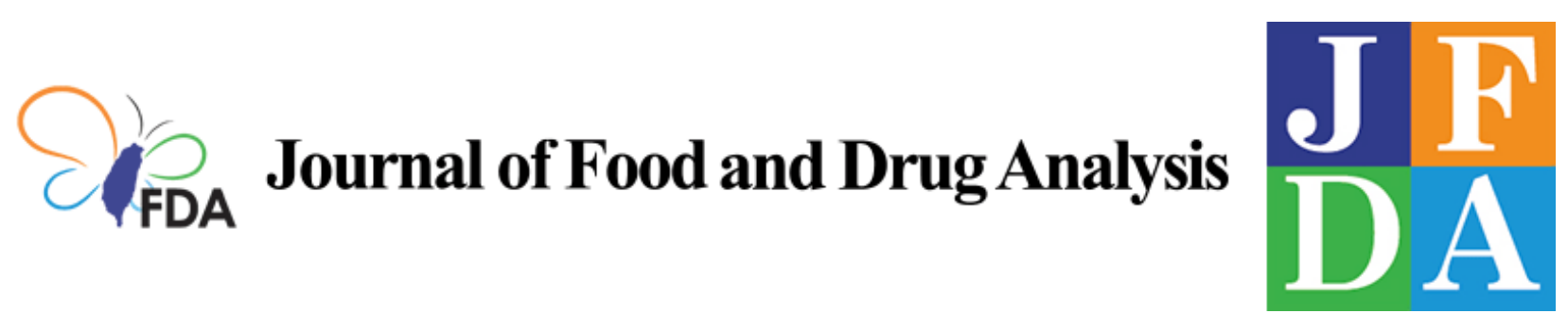

Volume 28 | Issue 4

Article 5

2020

\title{
Carbon quantum dots for the detection of antibiotics and pesticides
}

Follow this and additional works at: https://www.jfda-online.com/journal

Part of the Food Science Commons, Medicinal Chemistry and Pharmaceutics Commons, Pharmacology Commons, and the Toxicology Commons

(c) (i) (9)

This work is licensed under a Creative Commons Attribution-Noncommercial-No Derivative Works 4.0 License.

\section{Recommended Citation}

Chu, Han-Wei; Unnikrishnan, Binesh; Anand, Anisha; Lin, Yang-Wei; and Huang, Chih-Ching (2020) "Carbon quantum dots for the detection of antibiotics and pesticides," Journal of Food and Drug Analysis: Vol. 28 : Iss. 4 , Article 5.

Available at: https://doi.org/10.38212/2224-6614.1269

This Review Article is brought to you for free and open access by Journal of Food and Drug Analysis. It has been accepted for inclusion in Journal of Food and Drug Analysis by an authorized editor of Journal of Food and Drug Analysis. 


\title{
Carbon quantum dots for the detection of antibiotics and pesticides
}

\author{
Han-Wei Chu a , Binesh Unnikrishnan a , Anisha Anand ${ }^{\text {, }}$ \\ Yang-Wei Lin ${ }^{b}$, Chih-Ching Huang ${ }^{a, c, d, *}$ \\ ${ }^{a}$ Department of Bioscience and Biotechnology, National Taiwan Ocean University, Keelung, 20224, Taiwan \\ ${ }^{\mathrm{b}}$ Department of Chemistry, National Changhua University of Education, Changhua City, 50007, Taiwan \\ ${ }^{c}$ Center of Excellence for the Oceans, National Taiwan Ocean University, Keelung, 20224, Taiwan \\ d School of Pharmacy, College of Pharmacy, Kaohsiung Medical University, Kaohsiung, 80708, Taiwan
}

\begin{abstract}
Carbon quantum dots (CQDs) are novel nanomaterials with interesting physical and chemical properties, which are intensely studied only in the last decade. Unique properties, such as its inherent fluorescent property, high resistance to photobleaching, high surface area, ease of synthesis, flexible choice of precursor, and surface tunability enable CQDs for promising application in biosensing. Therefore, it is highly useful in clinical, forensic, medical, food and drug analyses, disease diagnosis, and various other fields of biosensing. In addition, their fluorescence properties are tunable by the interaction with certain molecules via different mechanisms, which enables their application for sensing of those molecules, such as pesticides and antibiotics. The detection of antibiotics and pesticides is especially important as they are commonly used in both the medical and agricultural fields and can affect both humans and their environment. However, these molecules do not have a specific recognition element unlike for antibodies, proteins, enzymes, and other biomarkers. Thus, the fluorescence quenching mechanism alone cannot be applied as a sensing mechanism for the CQDs-based sensing of pesticides and antibiotics. In this review, we discuss the application of various CQDs, in the detection of antibiotics, pesticides (herbicide, fungicide, insecticide), and other medicinal drugs through various detection strategies and their current limitations.
\end{abstract}

Keywords: Carbon quantum dots, Fluorescence, Sensors, Agricultural chemicals, Medicinal drugs, Environment

\section{Introduction}

$\mathrm{C}$ arbon quantum dots (CQDs) or carbon dots (CDs) are zero-dimensional $(<10 \mathrm{~nm})$ carbon-based nanomaterials that emerged in the last decade, known for their small size and strong and tunable catalysis and fluorescence characteristics [1]. CQDs are generally described as monodisperse quasi-spherical nanoparticles with multilayered graphene core structure and a large amount of oxygen- and/or nitrogen-containing functional groups on the surface [1,2]. CQDs have commonly been classified, based on their internal and surface structures, into graphene quantum dots (GQDs; consist of one to few layers of graphene with wider lateral dimension), carbon nanodots (CNDs; consist of several graphene layers embedded in $\mathrm{sp}^{3}$ structure), and polymer dots (PDs; mainly polymeric structure without a crystalline core), each with their own characteristics [3]. Regardless of their classification, the chemical and physical properties of CQDs are highly dependent on the precursors as well as conditions for the preparation. A variety of treatments to the precursors during the synthesis of CQDs and modification of CQDs tune and grant the CQDs desired properties for different applications such as anti-pathogen, drug delivery, photocatalysis, and biosensing/bioimaging [4-7]. In particular, CQDs have attracted great attention

Received 30 May 2020; revised 8 July 2020; accepted 29 July 2020.

Available online 1 December 2020

* Corresponding author at: Department of Bioscience and Biotechnology, National Taiwan Ocean University, 2, Beining Road, Keelung, 20224, Taiwan.

E-mail address: huanging@ntou.edu.tw (C.-C. Huang). 
in biosensing due to their unique fluorescent and electrochemical properties [4]. This allows CQDs to be a potential alternative to traditional organic fluorescent dyes and semiconductor quantum dots (QDs) as a result of less biohazard [4-7].

The ease of preparation and modification of CQDs offers advantages not only in fine-tuning of their electronic and optical properties but also mediation of the interaction between CQDs and analytes leading to fluorescence quenching or enhancement. Due to the diverse surface structure of CQDs, they are known to be able to interact with many compounds and biomolecules via a variety of intermolecular interactions [8-11]. Examples include oligonucleotides (electrostatic, hydrogen bonding, and $\pi-\pi$ stacking interaction), proteins (electrostatic, hydrogen bonding, and hydrophobic interaction), and metal ions (hard-soft acid-base (HSAB) interactions). In addition, different types of CQDs respond to these molecules in different ways allowing for multiple sensing strategies, such as fluorescent quenching, the shift in the emission wavelength, and change in enzymatic activity.

Drug analysis and detection is an essential field of research due to the importance of monitoring drug concentration and their metabolites. Other than medicinal drugs, the detection of antibiotics and pesticides is especially imperative as they are commonly used in both medicine and agriculture and highly affect humans and the environment. Moreover, antibiotics detection is of special concern since it is used intensively in both medicinal and agricultural settings. Monitoring excessive antibiotic use whether in patients, animals or environment can be significant to understand and monitor the appearance of antibiotic resistance bacteria prevalent in the region [12-14]. It is not only antibiotic abuse in human medical settings that cause the development of drug resistance in bacteria, veterinary abuse of antibiotics is also a major derivation. Some even estimated that $80 \%$ of total antibiotics sold in the US are for veterinary use including those preemptively used on farm animals and live stocks [14]. Inherent toxicity of the antibiotics can also be a serious environmental hazard as several antibiotics are known to disrupt plant protein synthesis [14]. Screening for pesticides (including fungicide, insecticide, and herbicide) in the environment or on food products are also extremely crucial for human health, as consumption of pesticides can lead to or risk serious issues such as acute pesticide poisoning, Parkinson's disease, Alzheimer's disease, increase attention deficit hyperactivity disorder (ADHD) for children [15-17]. Traditional methods of detection such as cell culturing, gas chromatography (GC), and high-performance liquid chromatography (HPLC) require expensive and sophisticated instrumentation, complicated sample preparation processes, and tedious detection time [18]. CQDs, with their unique optical and catalytic characteristics, offers a promising approach for simple and rapid detection. In this review, we will go through the recent development of CQDs-based detection of various drugs namely, antibiotics, pesticides, and other medicinal drugs.

The structural diversity of CQDs gives rise to the complex and unique fluorescence property of the CQDs. Most researches consider the carbon-core states, surface defect states, and molecular states to be the main contributor to the intricate fluorescent property of CQDs $[19,20]$. The carbon-core states are the result of the separation of the valence and conduction band of the $\pi$-domain, mainly from the graphene core. The surface defect states caused by various surface functional groups are considered to be the main fluorescence mechanism of most CQDs. This multiple functional group combination leads to complex radiative relaxation, multicolor emissions, and excitation dependent emission. In addition, the heteroatomic doping (such as $\mathrm{N}, \mathrm{S}$, and B) are known to improve radiative recombination, and thus higher quantum yield of the surface defect states [21]. Fluorescent molecular states result from the fluorophores or chromophores on the surface of CQDs. The molecular states behave similar to organic dyes, which tend to produce sharp and intense fluorescence with high quantum yield, but poor photobleaching resistance. Three fluorescence states (carbon-core, surface defect, and molecular states) mutually affect each other to cause a very complex fluorescent property in most of CQDs.

Specific interaction of CQDs with many molecules, such as DNA, proteins, metal ions can cause quenching of fluorescence which can be utilized for the detection of analytes [4-7]. Static quenching is a possible quenching mechanism for CQDs upon interaction with the analytes. It occurs through the formation of a new ground state of analyte-CQDs complex after strong bonding interaction between them [22]. The fluorescence of the CQDs can also be quenched through dynamic collision with the quencher after the CQDs have been excited, causing non-radiative energy transfer [22]. Photoinduced electron transfer (PET) can also occur between the CQDs and analyte [22]. Electron rich/poor CQDs interact with analyte and may cause an electron jump from one structure to another. As a result, the electrons are unable to traverse its original path (electron dropped from the lowest unoccupied 
molecular orbital (LUMO) to the highest occupied molecular orbital (HOMO) of the CQDs) and are forced to traverse a new path. Depending on the direction of the electron transfer process, PET can be classified into oxidative electron transfer (CQDs acts as the electron donor) and reductive electron transfer (CQDs acts as the electron acceptor). For oxidative electron transfer, the electron tends to move from the LUMO of the CQDs to the LUMO of the quencher, for reductive electron transfer from the LUMO of quencher to the HOMO of the CQDs, either cases usually resulting in decreased fluorescence [23]. However, it is not only a contact-based quenching mechanism that was used in the detection of analytes. Other noncontact mechanisms such as the inner filter effect (IFE), fluorescence and chemiluminescence resonance energy transfer (FRET and CRET) can also be used in the detection of many analytes (Scheme 1). In addition, enzymes can also be incorporated into the detection platform to achieve greater specificity than just from CQDs alone (Scheme 2).

CQDs provide distinct advantages as sensing probes on grounds of their unique fluorescent and electrochemical properties, ease of synthesis, and wide range of customization. In the past decade, CQDs based sensors have seen much development and several review articles have been written on the advantages and advances of CQDs as sensing probes [11,24,25]. However, such review articles have a more general focus, and none are focused solely on the recent development in the detection of medicinal and agricultural chemicals. In this review we will be focused mainly on the detection of antibiotics and pesticides, the two most commonly used medicinal and agricultural chemicals.

\section{Detection of antibiotics}

Antibiotics are widely used in human and veterinary medicine to combat bacteria. Tetracycline (TC) are commonly used in animal husbandry and aquaculture, due to their low cost and high efficiency. However, the presence of antibiotics in food grains, vegetables, milk, and surface water have posed a threat to human health. Intake of tetracycline can develop bacterial drug resistance and adverse health effects such as renal toxicity and intolerance. Therefore, the detection of residual antibiotics in meat, dairy, and other food products is imperative. Colorimetric, fluorescent, and electrochemical methods, HPLC, and surface-enhanced Raman scattering are widely used for the detection of antibiotics in recent decades [26-29]. However, these methods are time-consuming with tedious sample pre-treatment procedures and require sophisticated instruments. Semiconductor QDs, metal-organic frameworks, gold nanoclusters, and other inorganic phosphors with stable and strong emission properties have also been used for detecting antibiotics. However, they do have some limitations due to the poor water solubility, heavy metal pollution, and in some cases the photobleaching of the organic dyes. Therefore, recently, research interest has been shifted toward CQDs due to their exceptional properties as mentioned above.

The fluorescence behavior of CQDs and the fluorescence response upon binding to antibiotics are used to monitor the presence of antibiotics and to distinguish them. The specificity of fluorescence patterns for a particular antibiotic when it interacts with CQDs has been used for their detection [30]. CQDs upon interaction with antibiotics results in the enhancement or quenching of fluorescence [31]. Qian et al. have reported the use of near-infrared emissive CQDs for the detection of TC and quinolones [32]. In the presence of these antibiotics, the fluorescence of near-infrared emissive CQDs is highly depressed due to IFE. This quenching of fluorescence of the CQDs allows for the quantification of antibiotics, with a limit of detection (LOD) of $0.5 \mathrm{nM}$ for oxytetracycline and $6.3 \mathrm{nM}$ for norfloxacin. Whereas, aptamer modified gold nanoparticles (Au NPs) quench the fluorescence of CQDs in $\mathrm{NaCl}$ medium through IFE, however, the fluorescence of the CQDs is recovered in the presence of kanamycin through specific aptamer-kanamycin interaction, leading to the aggregation of $\mathrm{Au} \mathrm{NPs}$ [33].

Doping of CQDs with heteroatoms provides more active sites for the easy functionalization of CQDs, and the properties and reactivity of CQDs can be tuned for enhancing the sensing of antibiotics [3437]. For example, the pyrolysis of glutamic acid produces N-doped CQDs (NCDs), without the use of any external doping agent [38]. The decomposition of glutamic acid forms carbon- and nitrogenbased residues which simultaneously construct NCDs. The NCDs with an average size of $4.6 \mathrm{~nm}$, show excitation-dependent fluorescence, and are employed for the detection of a widely used antibacterial drug, amoxicillin. The fluorescence intensity of NCDs is enhanced and broadened in the presence of amoxicillin, with a significant blue shift. The non-radiative transition is decreased due to the adsorption of amoxicillin on the NCDs' surface, which decreases the energy transfer between the NCDs. Also, due to the binding of the drug on the NCDs, the surface defects of NCDs are diminished which in turn enhances the fluorescence intensity 
[38]. In the presence of metal ions, the addition of antibiotics to CQDs may result in the quenching of fluorescence or in the recovery of fluorescence in different degrees, which can be used as a transduction mechanism for detection of antibiotics [39]. CQDs from citric acid formamide (size 2.8 $\mathrm{nm}$ ) could detect oxytetracycline, down to $60 \mathrm{nM}$. The CQDs with abundant $-\mathrm{NH}_{2}$ and $-\mathrm{COOH}$ groups on their surface form chelating complexes with metal ions $\left(\mathrm{Cu}^{2+}, \mathrm{Ce}^{3+}\right.$, and $\left.\mathrm{Eu}^{3+}\right)$. However, in the presence of antibiotics, which also contain $-\mathrm{OH},-\mathrm{C}=\mathrm{O}$ and $-\mathrm{COOH}$ groups, compete for the interaction with the metal ions to form complexes, which affects the fluorescence of CQDs. This method has been proved to be efficient for the detection of antibiotics in shrimp and fish samples. Also, CQDs prepared from citric acid and urea, and modified with piperazine has been employed in the detection of oxytetracycline (Fig. 1) [40]. The fluorescent CQD showed a prominent redshift upon combining with oxytetracycline, which is explained due to the FRET between the CQDs and oxytetracycline. Enhancement in fluorescence intensity has been reported to be dependent on the $\mathrm{pH}$ and the concentration of oxytetracycline, however, no emission peak shift was reported upon increasing the concentration of oxytetracycline, which reveals that the fluorescence is due to the interaction of oxytetracycline with piperazine on the surface of the CQDs.

Various types of CQDs have been used for the detection of tetracycline by IFE [41]. CQD-based dual and quadruple-channel fluorescence sensing array could detect and distinguish various tetracycline-chlortetracycline, oxytetracycline, tetracycline, and doxycycline [42,43]. Blue-emitting CQDs (B-CDs; $\sim 3 \mathrm{~nm}$ ) prepared hydrothermally from citric acid and ethylenediamine, and greenemitting CQDs (G-CDs) prepared by microwave method from citric acid and urea $(\sim 16 \mathrm{~nm})$ were reported as efficient sensing elements. Fluorescence quenching of the CQDs occurs in the presence of tetracycline, however, without an emissive wavelength shift, due to IFE and each tetracycline could exhibit distinct variation in fluorescence intensity, allowing the differentiation of different tetracycline. However, a two-channel array having only the GCDs and B-CDs could not completely distinguish the four tetracyclines. Upon mixing the two CQDs (m-CDs), the m-CDs show the same absorption bands as the individual CQDs, but with enhanced values equal to the sum of the absorption values of B-CDs and G-CDs and could differentiate individual tetracyclines. Chlortetracycline could also be detected down to $3.30 \mathrm{nM}$ with CQDs prepared from $\mathrm{p}$-phenylenediamine and acetic acid by hydrothermal method, with size $2.4 \mathrm{~nm}$ emitting orange-red fluorescence [44]. Upon reacting with chlortetracycline, the CQDs show enhanced fluorescence, with a blue shift in ethanol medium, which may be due to aggregation-induced emission (AIE). However, in the presence of water, fluorescence quenching occurs due to depolymerizationinduced annihilation, and is proportional to the concentration of water and the detection limit for chlortetracycline was $32.9 \mu \mathrm{M}$. Thus, in addition to the detection of chlortetracycline, these CQDs may be employed to detect water content in organic solvents, which play a critical role in chemical reactions [44]. Europium-doped CQDs (Eu-CQDs) with high stability and blue-fluorescence are effective in the selective detection of tetracycline in water samples with a LOD of $0.3 \mu \mathrm{M}$ [45]. In the presence of tetracycline, the fluorescence of Eu-CQDs is quenched due to IFE between tetracycline and EuCQDs.

Fluorescence turn-on mechanism can also be used for the detection of antibiotics. The CQDs prepared from p-dihydroxybenzene and hydrazine hydrate by a hydrothermal treatment has been employed for the detection of ampicillin [31]. The blue fluorescence of CQDs is selectively quenched in the presence of $\mathrm{Fe}^{3+}$ ions due to the metal-ligand coordination and electrostatic interaction between the functional groups on CQDs and $\mathrm{Fe}^{3+}$. However, in the presence of ampicillin, under $365 \mathrm{~nm}$ UV irradiation, the non-fluorescent $\mathrm{CQD}-\mathrm{Fe}^{3+}$ complex display selective turn-on fluorescence with a LOD of $0.70 \mu \mathrm{M}$ for ampicillin. This CQDs can be also applied to detect tetracyclines due to the fluorescence quenching mechanism of the CQDs through $\pi-\pi$ interaction and electron transfer. The ratiometric sensing mechanism is an efficient strategy for improving the reliability of the sensor. CQDs with dual emission properties have been reported for the detection of penicillin $G$ in milk samples [46]. Blue and yellow emissive CQDs with molecularly imprinted receptors interact with penicillin $G$, the yellow emission is quenched due to blocking by the analyte (penicillin G), while the blue emission remains constant, enabling a radiometric readout.

In addition to CQDs prepared from various chemical sources, the CQDs prepared from natural sources are also found to be highly stable and effective in the detection of harmful antibiotics [4749]. Wang et al. reported the selective detection of amoxicillin with CQDs $(4-8 \mathrm{~nm})$ synthesized from beet using a hydrothermal method, without any additional agents [47]. The CQDs exhibit an excitation-dependent emission, with a redshift from $438 \mathrm{~nm}$ to $456 \mathrm{~nm}$, as the excitation wavelength 
(A)

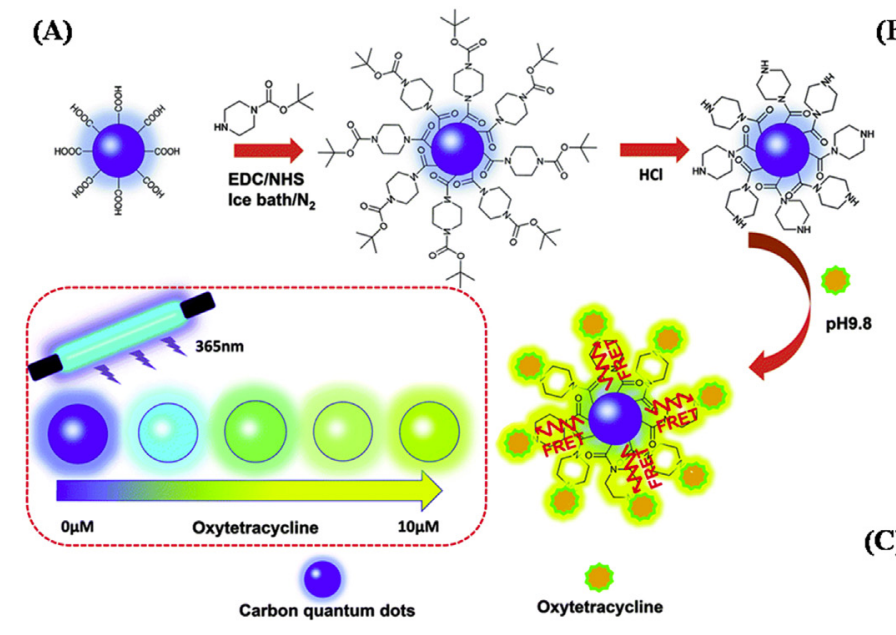

(B)

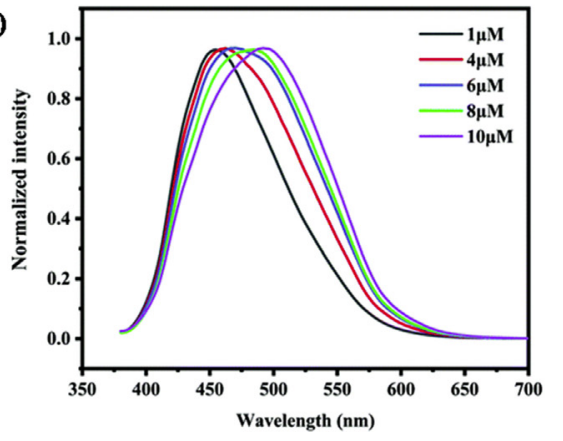

(C)

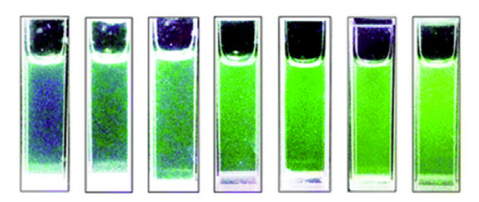

Fig. 1. (A) Schematic illustration of the synthesis of piperizine modified CQDs (P-CQDs) for visual detection of oxytetracycline. (B) Normalized fluorescence emission spectra and (C) photographs of P-CQDs with increasing concentrations of oxytetracycline. Reproduced with permission from Ref. [40].

changes from 340 to $400 \mathrm{~nm}$. Also, as the excitation wavelength is longer, the emission peaks first become strong and then weak, which may be due to the significant emissive traps distributed on the CQDs. The fluorescence of CQDs is enhanced when it interacts with amoxicillin with only very minor fluctuations in the presence of other interfering compounds such as glucose, sucrose, tryptophan, ascorbic acid, aspartic acid, L-cysteine, $\mathrm{NaF}$, $\mathrm{Ca}\left(\mathrm{NO}_{3}\right)_{2}$ and $\mathrm{KBr}$. The CQDs prepared from beet with a size of $6 \mathrm{~nm}$ can also be used for the detection of norfloxacin [48]. The CQDs with high stability and an excitation dependent fluorescence, when bound with norfloxacin, enhances the fluorescence of CQDs, and the lower LOD for the antibiotic was found to be $0.937 \mu \mathrm{M}$. Nitrogen-doped CQDs (NCQDs) prepared from durian shell waste with Tris base as a doping agent, by a hydrothermal method is reported to be highly selective toward the detection of tetracycline with a LOD of $75 \mathrm{nM}$ [49]. The quasi-spherical NCQDs with size $\sim 6.5 \mathrm{~nm}$ and quantum yield of $12.93 \%$ with blue fluorescence are stable under a wide $\mathrm{pH}$ range (3-11) and withstand photobleaching, however, affected by temperature. In the presence of tetracycline, fluorescence quenching of the NCDs occurs due to IFE. Recently, Guo et al. have reported the detection of tetracycline using fluorescent CQDs obtained by the thermal cracking of crab shell waste [50]. With an average size of $10 \mathrm{~nm}$ and $30 \%$ fluorescent quantum yield, the highly stable CQDs could detect tetracycline with a LOD $5 \mu \mathrm{g} \mathrm{L}^{-1}$.
In summary, fluorescent CQDs from various sources are found to be effective in the detection of antibiotics in various food materials. Table 1 lists the various CQDs used for the detection of antibiotics and their sensing mechanism. Though the strategy for the detection of antibiotics is based on the fluorescence 'turn on' or 'turn off' mechanism, which is a simple method, the selectivity of CQDs for a particular antibiotic narrows its usage. The selectivity of the CQDs-based sensing of antibiotics with similar structures and properties must be studied further. Also, the presence of other fluorescence quenching agents in the sample could tamper the result. Therefore, the specific interaction between CQDs and antibiotics must be investigated in detail for fabricating efficient antibiotic sensors.

\section{Detection of pesticides}

The main challenge in the detection of pesticides is the difficulty in finding natural or synthetic receptors or recognition elements. Most of the rapid detection of pesticides is achieved by monitoring their enzyme inhibition activity, however, a variety of pesticides can inhibit a particular enzyme leading to poor selectivity. However, with the recent development in 0-D nanomaterials, the interactions of pesticides with fluorescent CQDs have been reported to influence the fluorescence intensity depending upon the nature of interaction [51-55], which can be utilized as a transduction mechanism. Interaction of pesticides with CQDs leading to the 
Table 1. Type of CQDs, sensing mechanisms, and detection limits of various antibiotics.

\begin{tabular}{|c|c|c|c|c|c|c|c|}
\hline Carbon source & Type of CQD & Method of preparation & $\begin{array}{l}\text { Size and quantum } \\
\text { yield }\end{array}$ & Antibiotics & Detection mechanism & $\begin{array}{l}\text { Limit of } \\
\text { detection }\end{array}$ & Ref \\
\hline $\begin{array}{l}\text { p-dihydroxybenzene and } \\
\text { hydrazine hydrate }\end{array}$ & $\begin{array}{l}\text { CQDs in the } \\
\text { presence of } \mathrm{Fe}^{3+}\end{array}$ & Hydrothermal & $2.8 \mathrm{~nm} 0.59 \%$ & Ampicillin & $\begin{array}{l}\text { Binding of } \mathrm{Fe}^{3+} \text { to ampicillin } \\
\text { through electrostatic interaction and } \\
\text { metal-ligand coordination enhancing } \\
\text { the fluorescence }\end{array}$ & $0.70 \mu \mathrm{M}$ & $\overline{\text { [31] }}$ \\
\hline $\begin{array}{l}\text { Glutathione and } \\
\text { polyethylenimine }\end{array}$ & - & Solvothermal method & $4 \mathrm{~nm} 17.1 \%$ & $\begin{array}{l}\text { Oxytetracycline } \\
\text { and norfloxacin }\end{array}$ & Inner filter effect & $0.5 \mathrm{nM} 6.3 \mathrm{nM}$ & [32] \\
\hline Citric acid & - & Hydrothermal & $3.5 \mathrm{~nm}$ & Kanamycin & Inner filter effect & $18 \mathrm{nM}$ & [33] \\
\hline Rice residue & Nitrogen-doped CQD & Hydrothermal & $2.70 \mathrm{~nm} 23.48 \%$ & $\begin{array}{l}\text { Tetracycline, } \\
\text { terramycin, } \\
\text { chlortetracycline }\end{array}$ & $\begin{array}{l}\text { Interaction between CQD and } \\
\text { antibiotic resulting in quenching } \\
\text { of fluorescence }\end{array}$ & $\begin{array}{l}0.2367 \mu \mathrm{M}, \\
0.3739 \mu \mathrm{M}, \\
0.2791 \mu \mathrm{M}\end{array}$ & [34] \\
\hline Citric acid and L-cysteine & $\begin{array}{l}\text { Sulfur- and nitrogen- } \\
\text { doped CQD }\end{array}$ & $\begin{array}{l}\text { Solid-phase } \\
\text { hydrothermal method }\end{array}$ & $<10 \mathrm{~nm} 80 \%$ & Oxytetracycline & Chemiluminescence & $25 \mathrm{nM}$ & [35] \\
\hline Ethylenediamine & $\begin{array}{l}\beta \text {-cyclodextrin } \\
\text { functionalized } \\
\mathrm{N}, \mathrm{Zn} \text {-codoped CQD }\end{array}$ & Microwave digestion & $4-5 \mathrm{~nm} 14.26 \%$ & Ofloxacin & $\begin{array}{l}\text { Synergy of hydrogen bonding } \\
\text { interactions between cyclodextrin cavity } \\
\text { and the antibiotic and charge transfer } \\
\text { between } N \text {, Zn CQDs and the antibiotic }\end{array}$ & $0.05 \mu \mathrm{M}$ & [36] \\
\hline Fungus fiber & $\begin{array}{l}\text { Nitrogen, sulfur dual } \\
\text { doped CQD }\end{array}$ & Hydrothermal & $\begin{array}{l}6.5 \pm 0.5 \mathrm{~nm} \\
28.11 \%\end{array}$ & Tetracycline & Static quenching and inner filter effect & $15.6 \mathrm{nM}$ & [37] \\
\hline Glutamic acid & Nitrogen-doped CQD & One step pyrolysis & $4.6 \mathrm{~nm} 28 \%$ & Amoxicillin & $\begin{array}{l}\text { Interaction between CQDs and amoxicillin } \\
\text { showing enhanced fluorescence }\end{array}$ & - & [38] \\
\hline Citric acid formamide & - & $\begin{array}{l}\text { Microwave-assisted } \\
\text { solvothermal method }\end{array}$ & $2.8 \mathrm{~nm}$ & Oxytetracycline & $\begin{array}{l}\text { Multi-channel sensing based on } \\
\text { competing interaction of metal ions with } \\
\text { CQDs and antibiotics }\end{array}$ & $0.06 \mu \mathrm{M}$ & [39] \\
\hline Citric acid and urea & $\begin{array}{l}\text { Piperizine modified- } \\
\text { CQD }\end{array}$ & Hydrothermal & $25.06 \pm 6.51 \mathrm{~nm}$ & Oxytetracycline & Fluorescence resonance energy transfer & - & [40] \\
\hline $\begin{array}{l}\text { Citric acid and ethylene } \\
\text { diamine/citric acid } \\
\text { and urea }\end{array}$ & - & Hydrothermal/microwave & $3 \mathrm{~nm}$ and $16 \mathrm{~nm}$ & Tetracycline & Inner filter effect & $0.30 \mu \mathrm{M}$ & [43] \\
\hline $\begin{array}{l}\text { p-phenylenediamine and } \\
\text { acetic acid }\end{array}$ & Nitrogen-rich CQD & $\begin{array}{l}\text { One-pot solvothermal } \\
\text { carbonization }\end{array}$ & $2.4 \mathrm{~nm}$ & Chlortetracycline & Aggregation induced emission & $3.30 \mathrm{nmol} \mathrm{L}^{-1}$ & [44] \\
\hline $\begin{array}{l}\text { Europium nitrate } \\
\text { hexahydrate and } \\
\text { citric acid monohydrate }\end{array}$ & Europium-doped CQD & $\begin{array}{l}\text { Direct carbonization } \\
\text { in oil bath }\end{array}$ & $3.5 \mathrm{~nm} 4.7 \%$ & Tetracycline & Inner filter effect & $0.3 \mu \mathrm{M}$ & [45] \\
\hline Durian shell waste & Nitrogen-doped CQD & $\begin{array}{l}\text { One-pot hydrothermal } \\
\text { process }\end{array}$ & $6.5 \mathrm{~nm} 12.93 \%$ & Tetracycline & Inner filter effect & - & [49] \\
\hline Dried beet powder & - & Hydrothermal method & $4-8 \mathrm{~nm}$ & Amoxicillin & $\begin{array}{l}\text { Interaction between CQDs and amoxicillin } \\
\text { showing enhanced fluorescence }\end{array}$ & $0.475 \mu \mathrm{M}$ & [47] \\
\hline Crab shell waste & Nitrogen-rich CQD & Thermal cracking & $10 \mathrm{~nm} 30 \%$ & Tetracycline & $\begin{array}{l}\text { Combination of tetracycline with the surface } \\
\text { functional groups on CQD resulting in } \\
\text { fluorescence quenching }\end{array}$ & & [50] \\
\hline
\end{tabular}


perturbation of the recombination electron-hole pair, different types of charge transfer, energy transfer, and IFE can lead to fluorescence change of CQDs. Some pesticides could enhance the fluorescence of the CQDs, while some others quench the fluorescence. For example, imidacloprid strongly binds with CQDs through its $-\mathrm{NO}_{2}$ and $-\mathrm{NH}$ functional groups resulting in the breaking of selfcomplexation of the CQDs, thereby switching the CQDs to more isolated state, which enhances their fluorescence [51]. Thiabendazole, a benzimidazole fungicide, is found to enhance the fluorescence of CQDs embedded in silica molecularly imprinted polymers [56]. Whereas, pesticides like atrazine, chlorpyrifos, lindane, and tetradifon quench the fluorescence of the CQDs, through weak hydrogen, electrostatic or covalent bonding and substitution reaction, resulting in fluorescence quenching [51]. The report shows that the selectivity of the probe is based on the difference in the binding affinity of the pesticides with the CQDs. Pesticides like diazinon, amicarbazone, and glyphosate quench the fluorescence of green CQDs, synthesized from cauliflower juice by hydrothermal method, through FRET, with a LOD in $\mathrm{ng} \mathrm{mL}^{-1}$ level [57]. However, the CQDs could not distinguish when the three pesticides coexist in one solution, and therefore, the selectivity must be improved by modification of specific ligands on the CQDs. Doping of CQDs with multiple hetero atoms and flavonoid moiety has been reported to enhance their photoluminescent properties as well as selectivity and alter the sensing mechanism, toward various pesticides, such as fenitrothion, dithianon, dinoseb, and their structural analogs [58]. The authors demonstrate that the emission wavelength of the CQDs can be varied by increasing the number of types of heteroatoms $(\mathrm{N}$, $\mathrm{S}$, and $\mathrm{B}$ ), to match the absorption wavelength of the pesticide to achieve superior IFE. Magnetic silica beads modified with GQDs and molecularly imprinted polypyrrole have been reported to have high selectivity towards tributyltin [59]. The multifunctional and magnetic properties of the nanocomposite enable the enrichment of the analyte (i.e., tributyltin) leading to the quenching of fluorescence of the GQDs in the composite through electron transfer mechanism, with a LOD of $12.78 \mathrm{ppb}$. Conversely, Deka et al. reported the detection of pretilachlor by enhancement of fluorescence of CQDs obtained from water hyacinth [52]. The enhancement of the fluorescence upon the interaction of CQDs with pretilachlor is reported to be also due to the electron transfer mechanism.

When the pesticide could not directly alter the fluorescence of CQDs or have poor selectivity, a linking agent or a chemical reaction that can quench the fluorescence of CQDs can be incorporated for the detection of a particular pesticide. Peng et al. used pralidoxime as a linking agent for the interaction between fluorescent magnesium and nitrogen-codoped CQDs (Mg,N-CQDs) and paraoxon, in which the pralidoxime mediates the electron transfer between the CQDs and paraoxon leading to the quenching of fluorescence [60]. The $\mathrm{Mg}$, N-CQDs allows selective detection of paraoxon down to the nanomolar regime. As an example of using a catalysis reaction, $\mathrm{CeO}_{2}$ NPs can catalyze the decomposition of methyl-paraoxon into p-nitrophenol and phosphates [61,62]. The as-formed p-nitrophenol quench the fluorescence of CQDs through IFE. The approach of catalysis reaction coupled with CQDsbased IFE can selectively detect methyl-paraoxon as low as $24.7 \mathrm{ng} \mathrm{mL}^{-1}$. Fluorescent CQDs-Au nanoclusters ( $\mathrm{Au} \mathrm{NCs)} \mathrm{nanohybrid} \mathrm{system} \mathrm{has} \mathrm{been} \mathrm{re-}$ ported as a probe for the detection of carbendazim [63]. Au NCs quenches the fluorescence of the Ndoped CQDs through the FRET mechanism; however, when carbendazim is introduced, it interacts with the Au NCs and the CQDs remain free and the fluorescence is recovered. A similar pesticideinduced aggregation of $\mathrm{Au}$ NPs separating the CQDs-Au NPs pair is applied for the detection of cartap by Yang et al. [64]. The fluorescence of CQDs prepared from ashes of waste paper can be turnedoff by $\mathrm{Fe}^{3+}$ ions which is obtained by the oxidation of $\mathrm{Fe}^{2+}$ by $\mathrm{H}_{2} \mathrm{O}_{2}$ [53]. Organophosphorus pesticides are known to inhibit the activity of acetylcholinesterase, an enzyme widely used for pesticide sensing, which in turn inhibits the production of $\mathrm{H}_{2} \mathrm{O}_{2}$. The fluorescent CQDs coupled with $\mathrm{Fe}^{2+}$ and acetylcholine esterase/choline system could be employed for the detection of chlorpyrifos as low as $3 \mathrm{ng} / \mathrm{mL}$ [53]. In the absence of chlorpyrifos, $\mathrm{Fe}^{3+}$ quenches the fluorescence through coordination with the oxygen atoms on the CQDs, whereas in the presence of chlorpyrifos, conversion of $\mathrm{Fe}^{2+}$ to $\mathrm{Fe}^{3+}$ is inhibited, and thus the higher fluorescence intensity of the probe system. A similar "turn-off"/"turn-on" approach has been reported by Sahub et al. for the detection of organophosphate pesticide using GQDs and acetylcholinesterase and choline oxidase system [65]. The $\mathrm{H}_{2} \mathrm{O}_{2}$ produced by the acetylcholinesterase/choline oxidase system quenches the fluorescence of GQDs, however, in the presence of organophosphate pesticides, the enzymatic activity is inhibited, and the fluorescence of the GQDs is retained. The probe allows for the detection of dichlorvos as low as $0.172 \mu \mathrm{g} / \mathrm{mL}$. Similarly, N- and S-doped CQDs (N/S-CQDs) have been reported for the sensitive detection of carbaryl, with a LOD of 
$5 \mu \mathrm{g} / \mathrm{mL}$, in which acetylcholinesterase and choline oxidase enzymes are used for the production of $\mathrm{H}_{2} \mathrm{O}_{2}$ [66]. The two-enzyme reaction product $\mathrm{H}_{2} \mathrm{O}_{2}$ from acetylcholine chloride then quenches the fluorescence of the N/S-CQDs. The report shows that N/S-CQDs enable them to highly react with $\mathrm{H}_{2} \mathrm{O}_{2}$ leading to excellent sensitivity.

As an alternative strategy to enzyme-assisted $\mathrm{H}_{2} \mathrm{O}_{2}$-based response, $\mathrm{Li}$ et al. demonstrated that organophosphorus pesticide can be detected by monitoring the dopamine polymerization process in the presence of acetylcholinesterase and acetylthiocholine (Fig. 2) [67]. CQDs synthesized from citric acid and thiourea, emit red fluorescence $(610 \mathrm{~nm})$ (Fig. 2A). Dopamine polymerizes to form polydopamine that exhibits fluorescence at $503 \mathrm{~nm}$ and quenches the red fluorescence of CQDs through PET mechanism (Fig. 2B). In the presence of the enzyme (i.e., acetylcholinesterase), the enzymatic product (thiocholine) suppressed the polymerization process through its preferential adsorption toward dopamine and retains the CQDs fluorescence (Fig. 2C and D). However, organophosphorus pesticides such as paraoxon can inhibit the activity of the acetylcholinesterase, and therefore, the polymerization product quenches the fluorescence of CQDs. A radiometric measurement of the fluorescence of CQDs and polydopamine in presence of paraoxon is reported to be a reliable method for the detection in pg $\mathrm{mL}^{-1}$ level (Fig. 2E and F).

Gong et al. reported a FRET-based sensor for the detection of an organophosphate pesticide, by a "turn-off"/"turn-on" mechanism [68]. The schematic of the detection strategy and the response of the assay with paraoxon concentrations are displayed in Fig. 3. Nitrogen-doped CQDs interact with Au NPs through multiple $\mathrm{Au}-\mathrm{N}$ interaction resulting in the quenching of fluorescence through the FRET mechanism. The fluorescence quenching of CQDs is diminished by the thiocholine-induced aggregation of Au NPs obtained from the acetylcholinesterasemediated hydrolysis of acetylthiocholine. However,

(A)
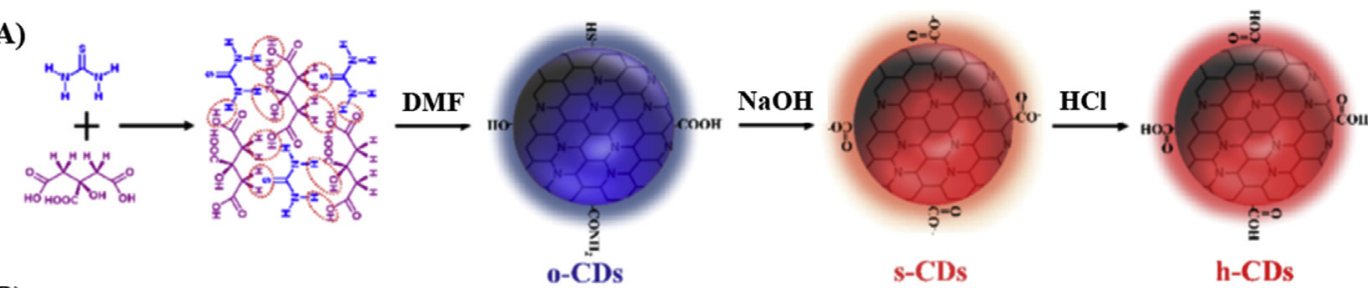

(B)
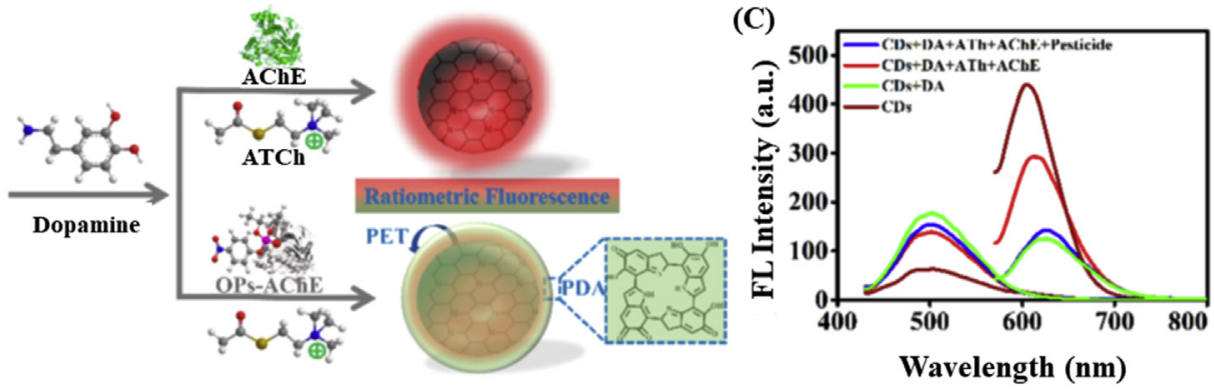

(D)

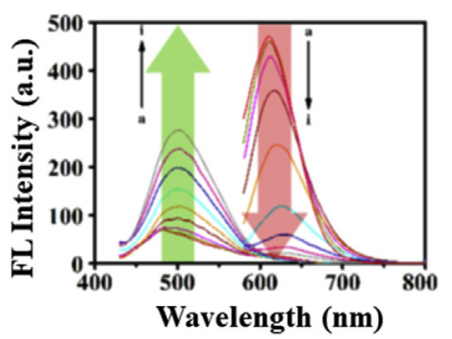

(E)

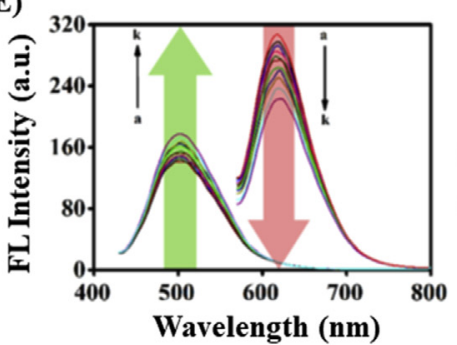

(F)

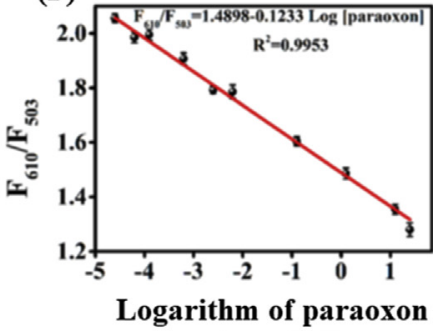

(ng mL $\mathbf{m}^{-1}$ )

Fig. 2. (A) Schematic representation of the synthesis of florescent CQDs. (B) Illustration of the detection strategy for organophosphorous pesticides using CQDs/dopamine-based sensor. (C) Fluorescence spectra of CQDs/dopamine in the absence and presence of acetylcholinesterase (AChE), acetylthiocholine (ATCh), and organophosphorus pesticides. (D) Fluorescence responses of CQDs-based probe in the presence of various concentrations of dopamine $\left(1.0-60 \mathrm{mmol} \mathrm{L}{ }^{-1}\right)$. (E) Fluorescence spectra and (F) relative fluorescence intensity of CQDs/dopamine-based sensor in the presence of various concentrations of paraoxon $\left(0.000025-25 \mathrm{ng} \mathrm{mL}^{-1}\right)$. Reproduced with permission from Ref. [67]. 

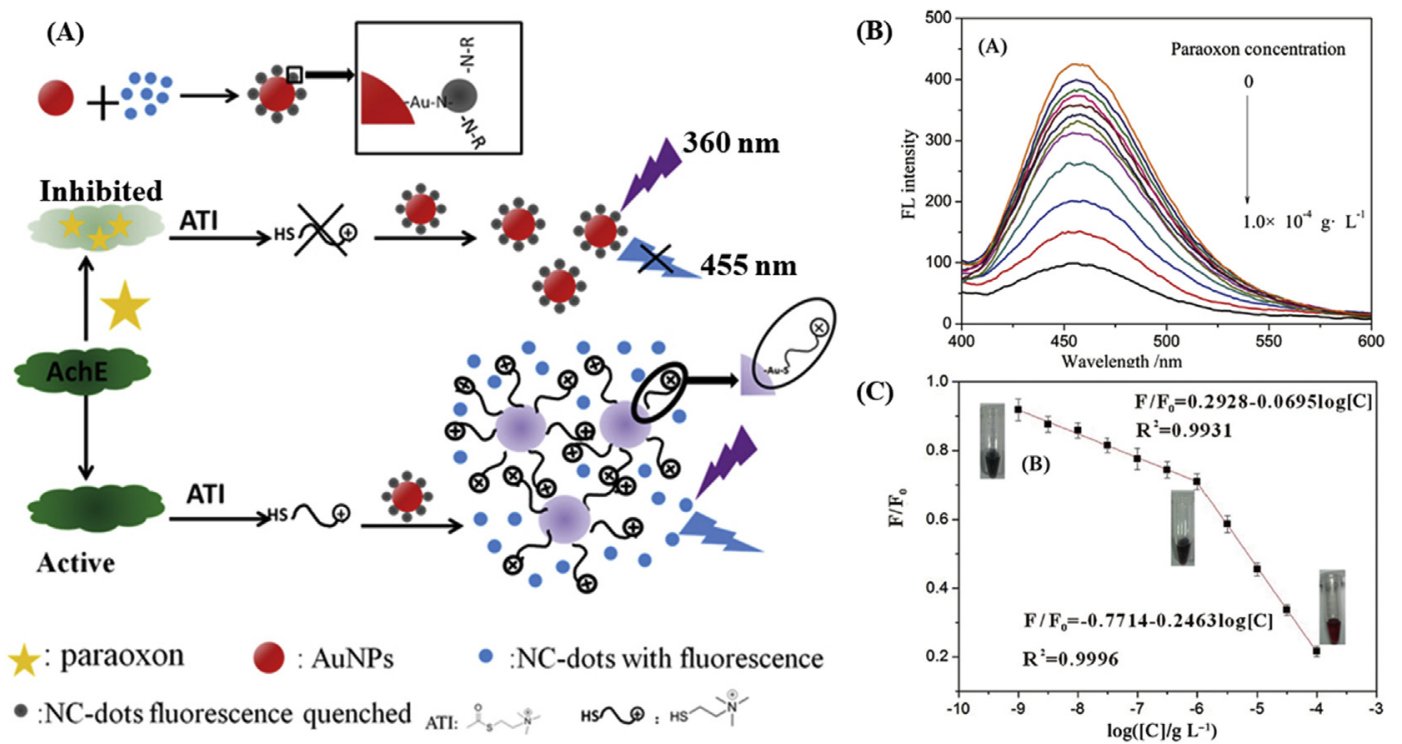

Fig. 3. (A) Schematic representation of the detection strategy for detection of paraoxon using nitrogen-doped CQDs (NC-dots)/Au NPs and acetylcholinesterase system assay. (B) Fluorescence specrta of the assay in presence of paraoxon at various concentrations, and (C) Plot of F/ $F_{0}$ against logarithm of paraoxon concentration. $F$ and $F_{0}$ are the fluorescence intensity of NC-dots in the absence and presence of paraoxon, respectively. Reproduction with permission from Refs. [68].

in the presence of organophosphorus pesticide, paraoxon, the enzyme activity of acetylcholinesterase is inhibited and the increased fluorescence intensity of CQDs is correlated to the concentration of the pesticide, enabling to detect paraoxon with a LOD of $3.6 \mathrm{pM}$. A very similar FRET mechanismbased detection strategy has been reported for the detection of organophosphorus pesticides by employing butyrylcholinesterase as the enzyme to hydrolyse acetylthiocholine [69]. The probe responses linearly with the logarithm of the concertation of the pesticide, enabling a LOD of $0.05 \mu \mathrm{g} \mathrm{L}^{-1}$.

As an alternative to the enzyme and to improve selectivity, aptamers are used as biorecognition elements in sensors. Aptamers are short DNA or RNA strands that are selected using a technique known as SELEX (systematic evolution of ligands by exponential enrichment) have been widely employed in many biosensors for the detection of biomarkers, pathogens, and diagnosis of serious diseases [7073]. To improve the specificity of pesticide sensors, pesticide-specific aptamer coupled with CQDs have been reported as a probe for the detection of acetamiprid [74]. The binding of the negatively charged aptamer with the cationic fluorescent CQDs synthesized from cetrimonium bromide (CTAB) results in their aggregation and fluorescence quenching. The complex of aptamer/CQDs is disintegrated in the presence of acetamiprid due to the strong acetamiprid-aptamer specific binding, leading to an increase in the fluorescence intensity of the CQDs. The probe is reported to detect acetamiprid down to $0.3 \mathrm{nM}$.

In addition to based on the fluorescence property of the CQDs, the colorimetric assay has been utilized for the detection of an insecticide, fenitrothion, by applying dispersive liquid-liquid microextraction (DLLME) method [75]. The CQDs extracted to the organic phase into carbon tetrachloride which is assisted by trioctylmethylammonium chloride, is improved by fenitrothion. Therefore, the absorbance increase of CQDs at $365 \mathrm{~nm}$ in the organic phase could be used for the determination of fenitrothion. Under the optimized conditions, the CQDs-based DLLME method allow selective detection of fenitrothion in the range of $1.0-250.0 \mathrm{ng} \mathrm{mL}{ }^{-1}$ with a LOD of $0.2 \mathrm{ng} \mathrm{mL}^{-1}$.

Table 2 lists the type of CQDs and the mechanism employed for the detection of pesticides and other drugs. In summary, the selectivity of a CQDs-based probe for the detection of pesticides depends on many factors, such as the surface functional groups on the CQDs, the quenching and binding constants of the target pesticides, and stoichiometry. The type of binding between the target pesticide and CQDs, and whether the interaction results in quenching or enhancement of fluorescence also depend on the type of functional group on the pesticide. Using a pesticide-specific linking substance that mediates the electron transfer from the CQDs to the pesticide 
Table 2. Type of CQDs, sensing mechanisms, and detection limits of various pesticides and medicinal drugs.

\begin{tabular}{|c|c|c|c|c|c|c|c|}
\hline Carbon source & Type of CQD & $\begin{array}{l}\text { Method of } \\
\text { preparation }\end{array}$ & $\begin{array}{l}\text { Size and } \\
\text { quantum yield }\end{array}$ & $\begin{array}{l}\text { Pesticides and } \\
\text { medicinal drugs }\end{array}$ & Detection mechanism & Limit of detection & Ref \\
\hline \multirow[t]{2}{*}{ Gelatin } & $\begin{array}{l}\text { CQDs with - } \\
\mathrm{NH}_{2},-\mathrm{COOH}, \\
\text { and -OH groups }\end{array}$ & Hydrothermal & $2.1-2.3 \mathrm{~nm}, 26.9 \%$ & Imidacloprid & $\begin{array}{l}\text { Analyte-induced switching } \\
\text { of CQDs from non-isolated } \\
\text { state to isolated state }\end{array}$ & $\begin{array}{l}0.013 \mu \mathrm{M} \\
0.04 \mu \mathrm{M}\end{array}$ & [51] \\
\hline & & & & $\begin{array}{l}\text { Atrazine, } \\
\text { chlorpyrifos, } \\
\text { lindane, } \\
\text { and tetradifon }\end{array}$ & Static quenching & & \\
\hline Waste paper ash & $\begin{array}{l}\text { CQDs with }-\mathrm{OH} \\
\text { groups and - } \\
\text { C-S bond }\end{array}$ & Hydrothermal & $2-4 \mathrm{~nm}, 20 \%$ & Chlorpyrifos & $\begin{array}{l}\text { Inhibition of } \mathrm{Fe}^{3+} \text {-induced } \\
\text { fluorescence quenching } \\
\text { (via inhibition of } \\
\text { acetylcholinesterase) }\end{array}$ & $3 \mathrm{ng} \mathrm{mL}^{-1}$ & [53] \\
\hline Water hyacinth & $\begin{array}{l}\text { CQDs with - } \\
\text { COOH, } \\
\text { and }-\mathrm{OH} \text { groups }\end{array}$ & Hydrothermal & $5.22 \mathrm{~nm}, 17.02 \%$ & Pretilachlor & $\begin{array}{l}\text { Electron transfer } \\
\text { induced fluorescence } \\
\text { enhancement }\end{array}$ & $2.9 \mu \mathrm{M}$ & [52] \\
\hline Citric acid and thiourea & $\begin{array}{l}\text { CQDs with amide, - } \\
\mathrm{COOH} \text {, and } \\
-\mathrm{OH} \text { groups }\end{array}$ & Solvothermal & $4-7 \mathrm{~nm}, 24.0 \%$ & $\begin{array}{l}\text { Paraoxon, } \\
\text { parathion, } \\
\text { and malathion }\end{array}$ & $\begin{array}{l}\text { Inhibition of } \\
\text { acetylcholinesterase- } \\
\text { mediated polymerization } \\
\text { of dopamine }\end{array}$ & $\begin{array}{l}0.025,0.0625, \text { and } \\
0.125 \mathrm{pg} \mathrm{mL}^{-1}\end{array}$ & [67] \\
\hline Cetrimonium bromide & $\begin{array}{l}\text { Acetamiprid aptamers- } \\
\text { modified CQDs }\end{array}$ & Hydrothermal & $1-2.5 \mathrm{~nm}, 20 \%$ & Acetamiprid & $\begin{array}{l}\text { Analyte-induced stripping } \\
\text { of surface aptamers leading } \\
\text { to restoring of fluorescence }\end{array}$ & $0.3 \mathrm{nM}$ & [74] \\
\hline Citric acid & $\begin{array}{l}{ }^{\mathrm{a}} \mathrm{GQDs} \text { with }-\mathrm{COOH} \text {, } \\
\text { and }-\mathrm{OH} \text { groups }\end{array}$ & Hydrothermal & $5 \mathrm{~nm}$ & Dichlorvos & $\begin{array}{l}\text { Inhibition of } \\
\text { acetylcholinesterase activity } \\
\text { to generate } \mathrm{H}_{2} \mathrm{O}_{2}\end{array}$ & $0.778 \mu \mathrm{M}$ & [65] \\
\hline Citric acid & $\begin{array}{l}\text { Magnetic silica beads } \\
\text { modified with GQDs } \\
\text { and molecularly } \\
\text { imprinted polypyrrole }\end{array}$ & Pyrolysis & $2.37 \mathrm{~nm}, 3.9 \%$ & Tributyltin & $\begin{array}{l}\text { Fluorescence quenching } \\
\text { via energy transfer }\end{array}$ & $12.78 \mathrm{ppb}$ & [59] \\
\hline Sugar cane juice & $\begin{array}{l}\text { CQDs with }-\mathrm{OH} \text { and } \\
-\mathrm{CH} \text { groups }\end{array}$ & Chemical & $<5 \mathrm{~nm}$ & Fenitrothion & $\begin{array}{l}\text { Dispersive liquid-liquid } \\
\text { microextraction (colorimetry) }\end{array}$ & $0.2 \mathrm{ng} \mathrm{mL}^{-1}$ & [75] \\
\hline Chlorophyll & $\begin{array}{l}\text { CQDs on Au } \\
\text { NP's surface }\end{array}$ & Hydrothermal & - & Paraoxon & $\begin{array}{l}\text { Inhibition of enzymatic } \\
\text { activity prevents recovery } \\
\text { of fluorescence quenched } \\
\text { by Au NPs through FRET }\end{array}$ & $0.05 \mu \mathrm{g} \mathrm{mL}^{-1}$ & [69] \\
\hline $\begin{array}{l}\text { Citric acid and } \\
\text { ethylenediamine }\end{array}$ & $\begin{array}{l}\text { N-doped CQDs } \\
\text { self-assembled } \\
\text { on Au NPs }\end{array}$ & Microwave & - & Paraoxon & $\begin{array}{l}\text { Inhibition of enzymatic } \\
\text { activity prevents the recovery } \\
\text { of fluorescence quenched } \\
\text { by Au NPs through FRET }\end{array}$ & $3.6 \mathrm{pM}$ & [68] \\
\hline $\begin{array}{l}\text { N-Methylethanolammonium } \\
\text { thioglycolate }\end{array}$ & $\begin{array}{l}\mathrm{N} \text { and S co- } \\
\text { doped CQDs }\end{array}$ & $\begin{array}{l}\text { Ultrasonic } \\
\text { treatment }\end{array}$ & $3-8 \mathrm{~nm}, 12.5 \%$ & Carbaryl & $\begin{array}{l}\text { Inhibition of acetylcholine } \\
\text { esterase activity prevents } \\
\mathrm{H}_{2} \mathrm{O}_{2} \text { production and thus } \\
\text { fluorescence quenching }\end{array}$ & $5.4 \mathrm{ng} \mathrm{L}^{-1}$ & [66] \\
\hline $\begin{array}{l}\text { Ammoniumpersulfate, } \\
\text { glucose, and } \\
\text { ethylenediamine }\end{array}$ & $\begin{array}{l}\mathrm{N} \text { and S-co- } \\
\text { doped CQDs }\end{array}$ & Hydrothermal & $2.81 \mathrm{~nm}, 21.6 \%$ & Methotrexate & $\begin{array}{l}\text { Fluorescence quenching } \\
\text { via FRET }\end{array}$ & $0.33 \mathrm{nM}$ & [54] \\
\hline
\end{tabular}




\begin{tabular}{|c|c|c|c|c|c|c|c|}
\hline Citric acid and L-cysteine & $\begin{array}{l}\mathrm{N} \text { and } \mathrm{S} \text { co- } \\
\text { doped CQDs }\end{array}$ & Hydrothermal & $5 \mathrm{~nm}, 52.7 \%$ & Methotrexate & $\begin{array}{l}\text { Inner filter effect induced } \\
\text { fluorescence quenching }\end{array}$ & $12 \mathrm{ng} \mathrm{mL}^{-1}$ & [55] \\
\hline \multirow{4}{*}{$\begin{array}{l}\text { Flavonoid extract, } \\
\text { ethylenediamine, } \\
\text { thiosemicarbazide } \\
\text { 3-boronobenzothioamide }\end{array}$} & \multirow{4}{*}{$\begin{array}{l}\mathrm{N}, \mathrm{S}, \mathrm{B} \text {, and flavanoid } \\
\text { moiety co-doped CQDs }\end{array}$} & \multirow[t]{4}{*}{ Hydrothermal } & \multirow[t]{4}{*}{$4.8-7.2 \mathrm{~nm}$} & \multirow{4}{*}{$\begin{array}{l}\text { Fenitrothion, } \\
\text { Dithianon, dinoseb }\end{array}$} & \multirow[t]{4}{*}{ Inner filter effect } & $0.36 \mathrm{nM}$ & \multirow[t]{4}{*}{ [58] } \\
\hline & & & & & & $0.28 \mathrm{nM}$ & \\
\hline & & & & & & $0.66 \mathrm{nM}$ & \\
\hline & & & & & & & \\
\hline Cauliflower juice & $\begin{array}{l}\text { CQDs with }-\mathrm{OH} \text { and } \\
-\mathrm{COOH} \text { groups }\end{array}$ & Hydrothermal & $4 \mathrm{~nm}$ & $\begin{array}{l}\text { Diazinon, } \\
\text { glyphosate, } \\
\text { amicarbazone }\end{array}$ & Fluorescence quenching & $\begin{array}{l}0.252 \mathrm{ng} \mathrm{mL}^{-1} \\
0.52 \mathrm{ng} \mathrm{mL}^{-1} \\
2 \mathrm{ng} \mathrm{mL}^{-1}\end{array}$ & [57] \\
\hline $\begin{array}{l}\text { Citric acid and } \\
\text { 3-aminobenzeneboronic acid }\end{array}$ & B, N-doped CQDs & Hydrothermal & $3-4 \mathrm{~nm}$ & Methyl-paraoxon & $\begin{array}{l}\text { Inner filter effect of P-nitrophenol } \\
\text { obtained by } \mathrm{CeO}_{2} \text { catalyzed } \\
\text { decomposition of methyl-paraoxon }\end{array}$ & $24.7 \mathrm{ng} \mathrm{mL}^{-1}$ & [61] \\
\hline Citric acid and $\mathrm{NH}_{4} \mathrm{OH}$ & N-doped CQDs & Hydrothermal & $4.5 \mathrm{~nm}$ & Carbendazim & $\begin{array}{l}\text { Recovery of fluorescence } \\
\text { of CQDs quenched by } \\
\text { Au NCs via FRET }\end{array}$ & $0.83 \mu \mathrm{M}$ & [63] \\
\hline Phenol and Ethylene diamine & CQDs with $\mathrm{C}-\mathrm{N}$ bonding & Hydrothermal & $3.37 \mathrm{~nm}, 29 \%$ & Cartap & $\begin{array}{l}\text { Recovery of fluorescence } \\
\text { of CQDs quenched by Au } \\
\text { NPs via inner filter effect }\end{array}$ & $3.8 \mathrm{nM}$ & [64] \\
\hline Alginic acid and $\mathrm{Mg}(\mathrm{OH})_{2}$ & $\mathrm{Mg}$ and $\mathrm{N}$ co-doped CQDS & Microwave & $3.5 \mathrm{~nm}, 33 \%$ & Paraoxon & $\begin{array}{l}\text { Fluorescence quenching of } \\
\text { CQDs via electron transfer } \\
\text { by paraoxon via pralidoxime- } \\
\text { mediated complexation }\end{array}$ & $0.87 \mathrm{nM}$ & [60] \\
\hline Sodium citrate and thiourea & $\mathrm{N}$ and $\mathrm{S}$ co-doped CQDs & Hydrothermal & $1.28-3.95 \mathrm{~nm}, 26.9 \%$ & Curcumin & $\begin{array}{l}\text { Inner filter effect induced } \\
\text { fluorescence quenching }\end{array}$ & $0.04 \mu \mathrm{M}$ & [83] \\
\hline $\begin{array}{l}\text { Ethylenediamine, } \mathrm{H}_{3} \mathrm{PO}_{4} \text {, and } \\
\text { 4-aminophenylboronic acid }\end{array}$ & P, N, B-co-doped CQDs & Hydrothermal & $5.74 \mathrm{~nm}, 21.95 \%$ & Curcumin & $\begin{array}{l}\text { Inner filter effect induced } \\
\text { fluorescence quenching }\end{array}$ & $68 \mathrm{nM}$ & [84] \\
\hline \multirow[t]{3}{*}{ 3,4-Dihydroxy-L-phenylalaine } & \multirow{3}{*}{$\begin{array}{l}\text { levoCQDs with }-\mathrm{NH}_{2},-\mathrm{OH} \\
\text { and-COOH, groups }\end{array}$} & \multirow{3}{*}{ Microwave } & \multirow[t]{3}{*}{$2.34 \mathrm{~nm}, 6.38 \%$} & \multirow{3}{*}{$\begin{array}{l}\text { i) } \mathrm{Cu}^{2+} \text { ii) Biothiols } \\
\text { iii) Curcumin }\end{array}$} & i) Static quenching ii) & i) $0.4 \mu \mathrm{M}$ ii) 0.92 & \multirow[t]{3}{*}{ [82] } \\
\hline & & & & & Recovery of fluorescence & $-3.17 \mu \mathrm{M}$ iii) & \\
\hline & & & & & $\begin{array}{l}\text { of levoCQDs-Cu }{ }^{2+} \text { by } \\
\text { biothiols iii) inner filter effect }\end{array}$ & $0.60 \mu \mathrm{M}$ & \\
\hline Dextrose and $\mathrm{HCl}$ & Amorphous CQDs & $\begin{array}{l}\text { Ultrasonic } \\
\text { treatment }\end{array}$ & $4-18 \mathrm{~nm}, 40 \%$ & 2,4,6-trinitrophenol & Energy and/or electron transfer & $0.2 \mu \mathrm{M}$ & [76] \\
\hline Glacial acetic acid and $\mathrm{P}_{2} \mathrm{O}_{5}$ & $\begin{array}{l}\text { Cross linked hollow } \\
\text { fluorescent CQDs }\end{array}$ & $\begin{array}{l}\text { Self-heating } \\
\text { autocatalysis }\end{array}$ & $100 \mathrm{~nm}$ & Dihydralazine & $\begin{array}{l}\text { Electron-transfer annihilation } \\
\text { and chemiluminescence } \\
\text { resonance energy transfer }\end{array}$ & $30 \mathrm{nM}$ & [81] \\
\hline L-arginine & N-containing CQDs & Hydrothermal & $4.4 \mathrm{~nm}, 16 \%$ & 4-chloroethcathinone & $\begin{array}{l}\text { Fluorescence quenching by } \\
\text { electron transfer process }\end{array}$ & $0.14 \mathrm{mM}$ & [77] \\
\hline Chitosan hydrogel & $\begin{array}{l}\text { CQDs functionalized } \\
\text { with } \mathrm{NaF}\end{array}$ & Microwave & $<5 \mathrm{~nm}$ & Retinoic acid & $\begin{array}{l}\text { Charge transfer induced } \\
\text { diminishing of fluorescence }\end{array}$ & - & [79] \\
\hline Zein biopolymer & $\begin{array}{l}\text { 3,5-dinitro benzoyl } \\
\text { chloride-conjugated CQDs }\end{array}$ & Direct pyrolysis & $4-9 \mathrm{~nm}, 26 \%$ & Sumatriptan & $\begin{array}{l}\text { Analyte induced } \\
\text { fluorescence quenching }\end{array}$ & $0.32 \mathrm{nM}$ & [78] \\
\hline Ascorbic acid and kollicoat & Au@CQD & Microwave & $7 \mathrm{~nm}$ & 6-Thioguanine & $\begin{array}{l}\text { Recovery of the fluorescence of } \\
\text { the CQDs via analyte-induced } \\
\text { aggregation of Au NPs }\end{array}$ & $0.01 \mu \mathrm{M}$ & [80] \\
\hline Rosemary leaves & $\begin{array}{l}\text { CQDs modified with } \\
\text { molecularly imprinted } \\
\text { polymers }\end{array}$ & Hydrothermal & $5 \mathrm{~nm}, 28 \%$ & Thiabendazole & $\begin{array}{l}\text { Enhanced fluorescence of the } \\
\text { CQDs by thiabendazole by altering } \\
\text { non-radiative recombination }\end{array}$ & $8 \mathrm{ng} \mathrm{mL}^{-1}$ & [56] \\
\hline
\end{tabular}

${ }^{a}$ Graphene quantum dots. molecularly imprinted non-radiative recombination 
(A)<smiles>O=C(O)CC(O)(CC(=O)O)C(=O)O</smiles>

Fluorescent probe turn on
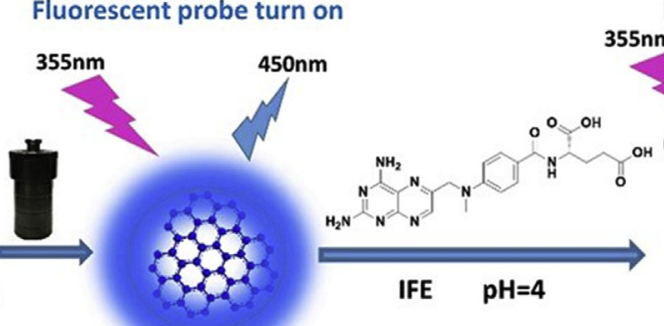

Fluorescent probe turn off m

(B)

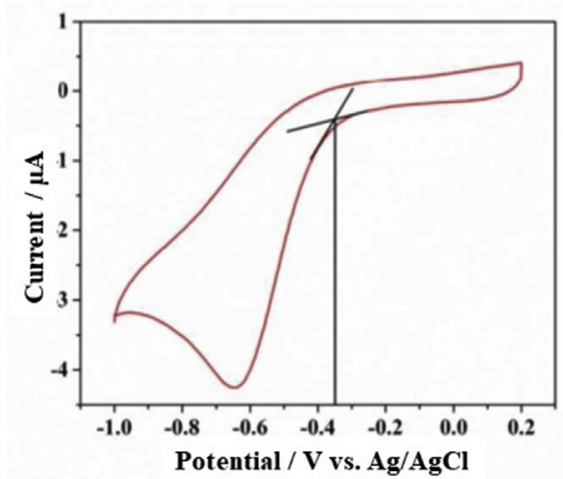

(C)

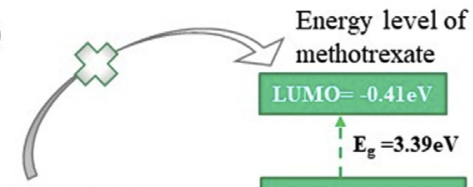

Energy level of NSCDs HOMO $=-3.80 \mathrm{eV}$

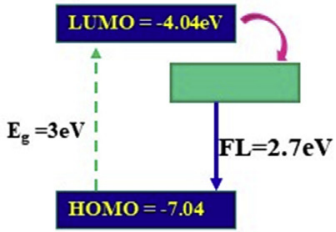

Fig. 4. (A) Schematic representation of synthesis of N,S co-doped CQDs for the detection of methotrexate. (B) Cyclic voltammogram of N,S co-doped CQDs in potassium hydrogen phthalate buffer solution $(\mathrm{pH} 4)(\mathrm{C})$ Schematic illustration of HOMO and LUMO energy levels of N,S co-doped CQDs and methotrexate. Reproduced with permission from Ref. [55].

(A)

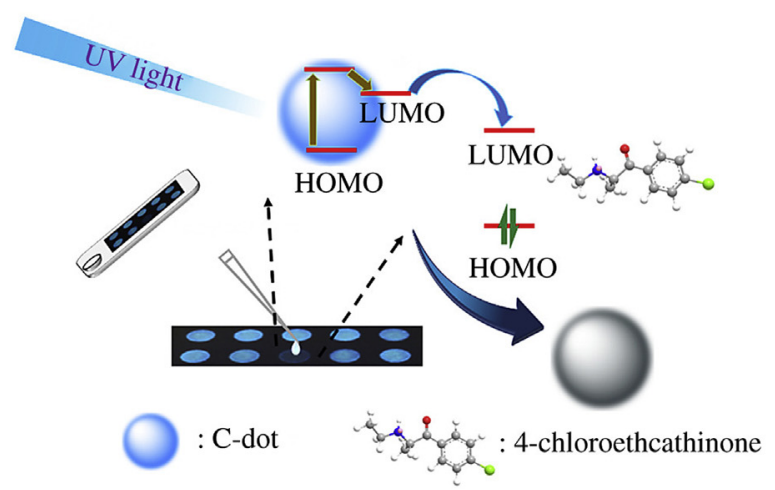

(B)

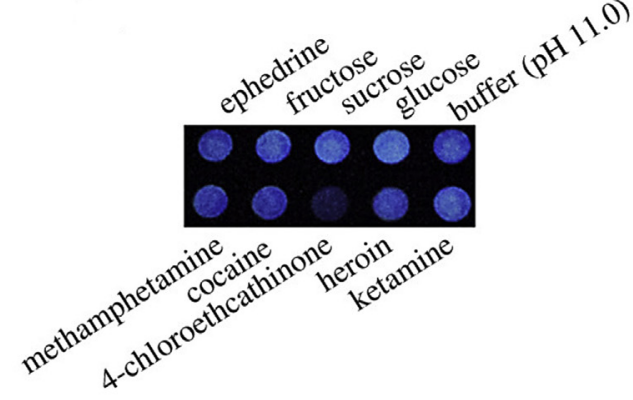

(C)

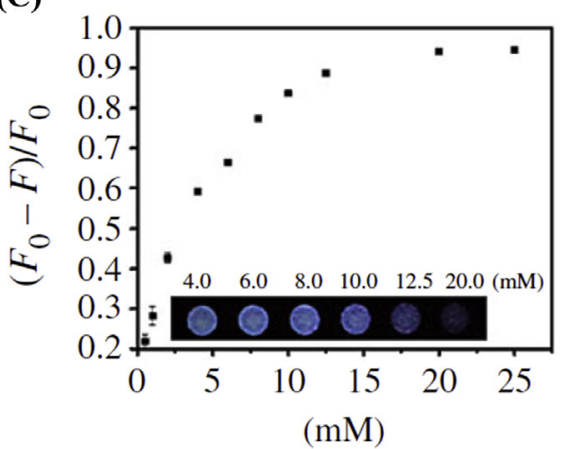

Fig. 5. (A) Schematic representation of CQD-based paper assay for the detection of 4-cholorethcathinone. (B) The selectivity of CQD-based paper assay illuminated with a hand-held UV-lamp. (C) Quantitation of 4-chloroethcathinone at the concentrations ranging from 0.5 to $25.0 \mathrm{mM}$ by CQDbased paper assay. Reproduced with permission from Ref. [77]. 
(A)
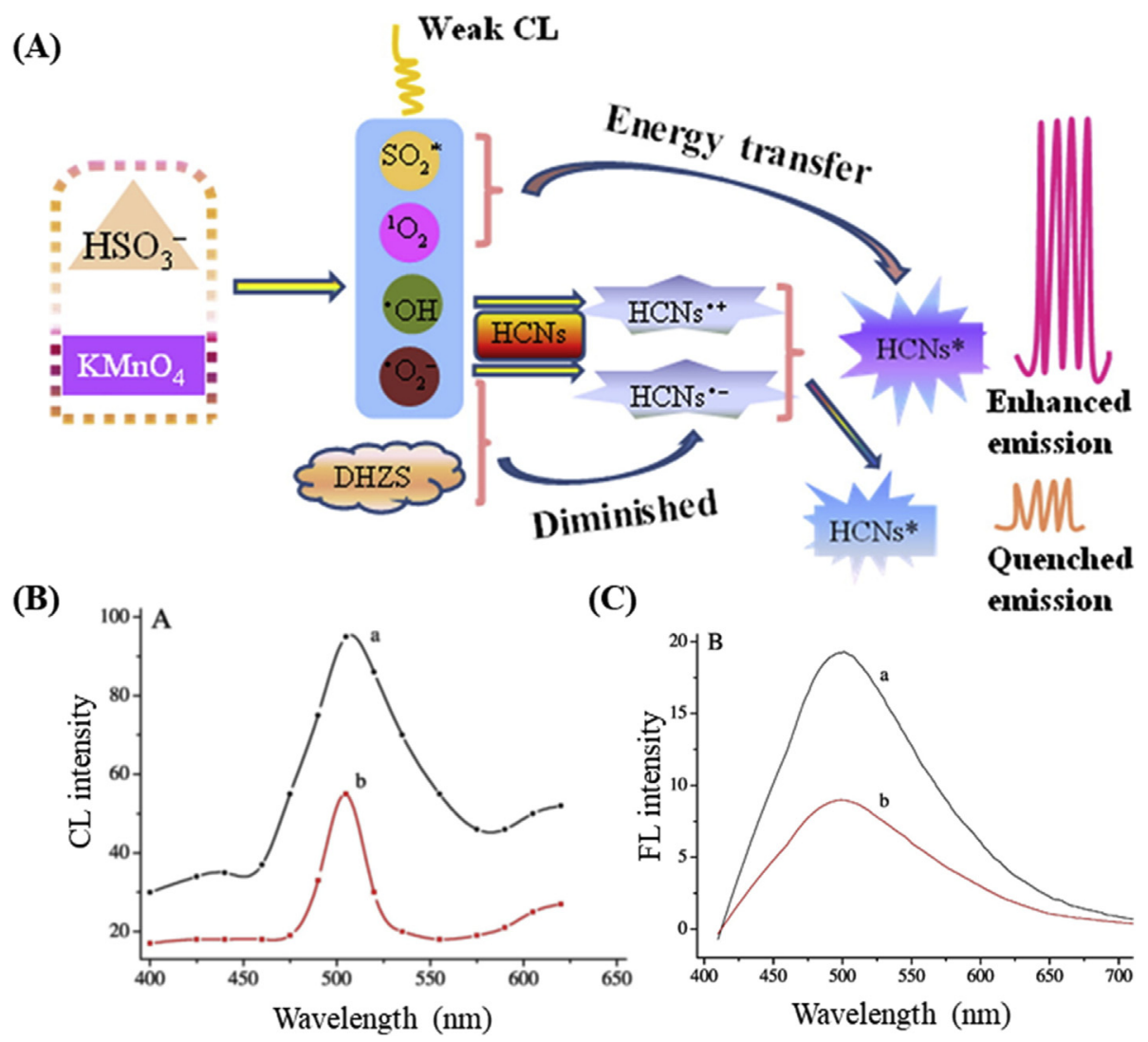

Fig. 6. (A) Schematic illustration of CRET-based sensing mechanism. (B) CL and (C) fluorescence spectra of (a) $\mathrm{KMnO}_{4}-\mathrm{HSO}_{3}^{-}-\mathrm{HCNs}$ and (b) $\mathrm{KMnO}_{4}-\mathrm{HSO}_{3}^{-}-\mathrm{HCNs}$-dihydralazine systems. Reproduced with permission from Refs. [81].

can enhance the selectivity of the CQDs-based probe. By monitoring the inhibition of enzyme activity by a pesticide, in which one of the products (for example, $\mathrm{H}_{2} \mathrm{O}_{2}$ ) influences the fluorescence properties of the CQDs, can be used as a strategy for the detection of pesticides. CQDs modified with molecularly imprinted polymers with pesticidespecific properties are found to be effective in improving the selectivity of the CQDs toward pesticides. Similar to the detection of many biomarkers and pathogens, pesticide-specific aptamers can be designed for developing CQD-based pesticide sensors, however, this method is least explored and need further research. The specific chemical reaction between CQDs and some molecules leading to quenching of fluorescence and then fluorescence turn-on upon interaction by pesticide can be a useful approach. Ratiometric sensing using of two fluorophores with two different emissions have been constructed to be a reliable method for pesticide sensing. In general, this review suggests that pesticides with very similar chemical structures can tamper the results of CQD-based sensors. Developing pesticide-specific aptamers and antibodies are a viable option to overcome the selectivity issues.

\section{Detection of other medicinal drugs and important molecules}

In addition to antibiotics and pesticides, fluorometric detection of a handful of medicinal drugs and other important molecules by CQD-based probes have been reported. The response mechanisms are found to be similar to the above-mentioned ones, such as FRET, PET, and IFE. N and S-codoped CQDs, obtained from ammonium persulfate, glucose, and ethylenediamine, with blue fluorescence emission and quantum yield of $21.6 \%$ has been reported to suffer significant fluorescence quenching by the interaction of methotrexate through FRET mechanism, enabling its detection as low as $0.33 \mathrm{nM}$ [54]. The selectivity and signal response of the probe is reported to be due to the strong hydrogen bonding between the CQDs and methotrexate leading to FRET. Zhao et al. reported similar $\mathrm{N}$ and S-codoped CQDs prepared from citric acid and L-cysteine as a probe for the detection of 
Photoinduced Electron Transfer (PET)

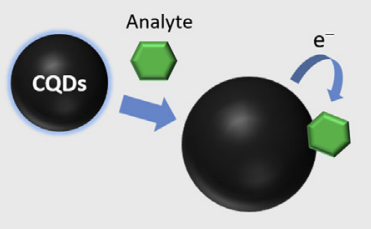

Resonance Energy Transfer (FRET/CRET)

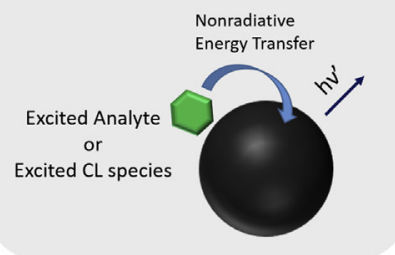

Inner filter effect (IFE)

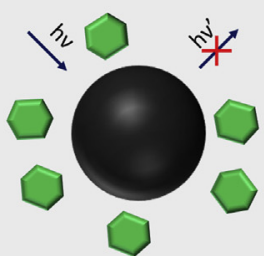

Scheme 1. CQDs-based FRET, IFE, PET, and CRET detection.

the same drug, methotrexate by fluorescence quenching, however, the response mechanism is reported to be IFE (Fig. 4) [55]. The specific interactions are through the hydrogen bonding between various surface functional groups of the N,S co-doped CQDs and methotrexate and $\pi-\pi$ stacking between aromatic heterocyclic carbon core of the CQDs and pteridine ring or phenyl group of methotrexate (Fig. 4A). The energy levels of the LUMO and the HOMO of the CQDs are measured by cyclic voltammogram (Fig. 4B). Photoexcited electrons in the CQDs are not energetically allowed to transfer to the LUMO of methotrexate, thereby the authors excluded the PET between CQDs and methotrexate (Fig. 4C). The FRET mechanism also is excluded because of strong electrostatic repulsion between the CQDs (zeta potential $20 \mathrm{mV}$ ) and positively charged methotrexate ( $p \mathrm{Ka} 4.5-5.8)$ in potassium hydrogen phthalate $(\mathrm{pH} 4)$ buffer solution. Therefore, the authors suggest IFE is the major mechanism responsible for the fluorescence quenching of CQDs by methotrexate.

Amorphous fluorescent CQDs prepared from dextrose and $\mathrm{HCl}$ by simple ultrasonication have been reported to be efficient for the detection of 2,4,6-trinitrophenol [76]. The report claims that the probe can be used to detect trinitrophenol with the naked eye in the range of $0.5-200 \mu \mathrm{M}$, with a LOD of $0.2 \mu \mathrm{M}$. The response mechanism of the CQDs upon interaction with 2,4,6-trinitrophenol has been suggested to be by FRET, charge transfer, and IFE.
However, other nitro compounds also can quench the fluorescence with different rates. And therefore, a detailed study on the interaction of nitro-compounds with CQDs and quenching mechanism is needed.

CQD-based fluorescence assays are not only useful for liquid state assays but also for paperbased assays. Yen et al. prepared fluorescent CQDs from L-arginine by a hydrothermal method and showed that the CQDs experience significant fluorescence quenching upon interaction with $\pi$-conjugated keto compounds through the electron transfer process, enabling their sensing (Fig. 5A) [77]. Coating of the CQDs on a paper enables the selective detection of compounds, such as 4-chloroethcathinone and its analogous with the naked eye with a portable UV-lamp (Fig. 5B). The fluorescence intensity of CQDs on paper is decreased upon increasing the concentration of 4-chloroethcathinone with a linear range from 0.5 to $10.0 \mathrm{mM}$.

The sensitivity of a CQD based probe can be improved by functionalizing with a suitable molecule that possesses a higher affinity toward the analyte. For example, CQDs synthesized from zein biopolymer and conjugated with 3,5-dinitro benzoyl chloride (DNB) have been used for the detection of sumatrip$\tan$ [78]. Sumatriptan quenches the fluorescence of DNB-CDs more effectively than unmodified CDs, leading to improved sensitivity and selectivity. The mechanism of fluorescence quenching is reported to
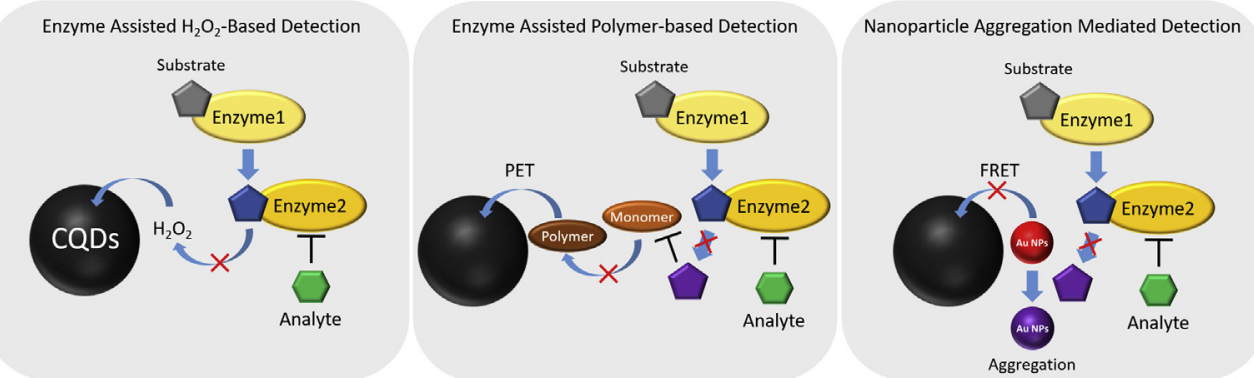

Scheme 2. Enzyme incorporated into the CQDs-based sensors. 
be through the interaction of nitro-group of DNB and amino-group of sumatriptan through hydrogen bonding. Surface modification of fluorescent CQDs can also enhance their fluorescence properties which will increase the sensitivity along with the selectivity. Majumdar et al. developed a selective probe for the detection of retinoic acid by CQDs synthesized from chitosan and conjugated with fluoride ions [79]. The addition of fluoride ions to the CQDs causes electron transfer from the CQDs to the fluoride due to the inductive effect of fluoride, resulting in boosting the fluorescence of CQDs. When retinoic acid is added to the fluoride/CQDs system, charge transfer from retinoic acid to fluoride takes place and thus the charge transfer from CQDs to fluoride is disrupted, leading to diminished fluorescence. The authors noted that fluoride enhances sensitivity as well as selectivity of the CQDs for the detection of retinoic acid, due to the specific inductive effect of fluoride ions.

In addition to utilizing the direct interaction of the drugs or other molecules with the CQDs or functionalized CQDs, "turn-off"/"turn-on" strategy using a common molecule or metal species that can react with both CQDs and analyte competitively may be employed for the detection of drugs. Conjugating gold atoms to CQDs can be an efficient method for turn-off/turn-on fluorescence mechanism for the detection of analyte that can be reacted with gold atoms, especially thiol drugs [80]. CQDs synthesized from ascorbic acid and Kollicoat-IR (polyvinyl alcohol/polyethylene glycol graft copolymer), and in situ formation of Au core with CQDs shell by a one-step microwave-assisted method has been reported to be applied for the sensing of 6thioguanine (6-TG). The formation of Au core decreases the fluorescence of CQDs by approximately 96\% through the energy transfer mechanism. However, 6-TG forms complex with Au through strong $\mathrm{Au}-\mathrm{S}$ bonding resulting in the release of the CQDs, thereby, boosting the fluorescence.

In addition to utilizing the fluorescence properties of CQDs for the detection of various drugs, the ability of the hollow fluorescent carbon nanodots (HCNs) to interact with chemiluminescence (CL) systems also has been reported as a transduction mechanism for the sensing of dihydralazine, as illustrated in Fig. 6 [81]. Han et al. synthesized $\mathrm{HCNs}$ by the exothermic reaction of glacial acetic acid and $\mathrm{P}_{2} \mathrm{O}_{5}$ and reported that they can enhance $\mathrm{CL}$ of $\mathrm{KMnO}_{4}-\mathrm{HSO}_{3}^{-}$system (Fig. 6A). The $\mathrm{KMnO}_{4}-\mathrm{HSO}_{3}^{-}$system produces weak $\mathrm{CL}$ through the formation of free radicals and excited species such as $\mathrm{OH}, \mathrm{O}_{2}^{-},\left({ }^{1} \mathrm{O}_{2}\right)_{2}{ }^{*}$, and $\mathrm{SO}_{2}{ }^{*}$. HCNs interact with all of these species and the excited form of $\mathrm{HCNs}$ are produced (HCNs*) through electron- transfer annihilation and CL resonance energy transfer (CRET), which has enhanced fluorescence properties. However, in the presence of dihydralazine, a competitive consumption of $\bullet \mathrm{O}_{2}^{-}$by $\mathrm{KMnO}_{4}-\mathrm{HSO}_{3}^{-}$system leads to diminish fluorescence (Fig. 6C), enabling an efficient sensing system with a LOD of $30 \mathrm{nM}$. The report claims the probe can detect dihydralazine in pharmaceutical preparations, human urine, and plasma samples [81].

If different analytes can interact with one type of CQD and quench the fluorescence through different mechanisms, then the CQD can be used as a multifunction probe for the detection of those analytes. For example, fluorescent CQDs synthesized from 3,4-dihydroxy-L-phenylalaine (LevoCQDs) have been used as a multifunctional probe for the detection of copper ion, biothiols, and curcumin [82]. The report shows that $\mathrm{Cu}^{2+}$ ions significantly quench the fluorescence, through complexation with LevoCQDs, in a wide range of concentrations from 4 to $60 \mu \mathrm{M}$ with a LOD of $0.4 \mu \mathrm{M}$. In addition, biothiols such as glutathione, cysteine, and homocysteine dissociate the $\mathrm{Cu}^{2+}$-levoCQDs complex through a competitive complexation, resulting in the recovery of the fluorescence. Therefore, the $\mathrm{Cu}^{2+}$ levoCQDs complex can be used as a probe for the detection of biothiols. In addition, the fluorescence of levoCQDs can be quenched by curcumin via IFE due to the overlap of its excitation spectrum with the absorption of curcumin. Furthermore, the levoCQDs can also track the formation of $\mathrm{Cu}^{2+}$-curcumin complexes. The fluorescence of levoCQDs in curcumin solution was increased upon adding $\mathrm{Cu}^{2+}$ as a result of the formation of $\mathrm{Cu}^{2+}$-curcumin complexes. The authors claimed this study can exploit the formation mechanism of $\mathrm{Cu}^{2+}$-curcumin complexes in the treatment of Alzheimer's disease. Han et al. also reported that curcumin can quench the fluorescence of $\mathrm{N}, \mathrm{S}$-codoped CQDs synthesized from sodium citrate and thiourea, through IFE that allows for curcumin sensing in the range of $0.15-18.0 \mu \mathrm{M}$ [83]. In addition to the sensing of curcumin, the CQDs has been reported to exhibit a temperature-dependent fluorescence with an inverse relationship in the range of $5-70{ }^{\circ} \mathrm{C}$. However, the mechanism behind temperature-dependent fluorescence properties of the CQDs is yet to be identified. $W u$ et al. reported a similar behavior of $P$, $\mathrm{N}$ and B-co-doped CQDs synthesized from ethylenediamine, $\mathrm{H}_{3} \mathrm{PO}_{4}$, and 4-aminophenylboronic acid as a probe for the detection of curcumin through IFE induced quenching, and also as a temperature sensor [84]. The authors suggest that the temperature-dependent fluorescence behavior of the CQDs could be due to the increased 
probability of collision among particles causing aggregation at higher temperatures.

In summary, many medicinal and recreational drugs of abuse can be detected using fluorescent CQD-based assays. The selectivity of the assay mainly depends on the physical interaction between CQDs and the drugs. The selectivity can thus be improved by tuning the surface functional groups of the CQDs to specifically interact with the drugs, which results in quenching of fluorescence through various mechanisms (Table 2). In addition, certain CQDs exhibit different interaction with different drugs at different $\mathrm{pH}$, which can be utilized as a strategy for the detection of multiple drugs with the same assay. Interaction of the fluorescent CQDs with chemiluminescence systems resulting in enhancement of fluorescence properties can also be used as a mechanism for the detection of drugs. However, CQDs still suffer from selectivity issues, and the potential of CQDs for the detection of drugs has not been well utilized, and further studies are needed for improving selectivity.

\section{Future prospective}

The recent development in CQDs-based sensing reveals their high possibility for widespread application in the future. Despite the advantages the CQDs-based sensing brings, they are rarely applied for sensing of antibiotics, pesticide, or other drugs in real-time analysis. The detection is mainly performed by more traditional methods such as HPLC, GC-MS, and LC-MS. The two major issues that CQDs-based sensors suffer from are selectivity and sensitivity. The lack of a robust recognition element on CQDs limits their selective target to the analyte in real samples. Therefore, future work must highly focus on developing CQDs with specific interaction with a particular analyte. The functionalization of CQDs with a well-produced antibody is an alternative approach to improve selectivity. However, it is difficult to raise an excellent antibody for drugs or pesticides since many of them are small molecules, and pesticides or drugs with similar structures will have similar affinities toward CQDs. The main advantage of core-shell and optical properties of CQDs lies in their diverse and varying preparation methods, conditions, and precursors, which allow researchers to easily tune the properties of the CQDs for recognizing certain analytes. The mixture of multiple precursors having high affinity toward target molecules for the preparation of CQDs and well control in the polymerization and carbonization in the preparation for high preservation of the structure of precursors will endow the obtained CQDs possess high specificity to analytes.

CQDs are not individual molecules or definite supramolecular structures, and are mostly composed of complex mixtures of fluorescent carbon-based nanoparticles with differing sizes, shapes, and surface functional groups. It is impossible to synthesis CQDs with precise structure with the mainstream methods, such as microwaveassisted process, dry heating, hydrothermal, and solvothermal methods. While CQDs with strictly defined structure can produce extremely sharp fluorescence peaks, most CQD mixtures have broad fluorescence peaks which limit their multiplex applications. Much progress and great effort had been made in the understanding of the fluorescent centers and electrochemical properties of CQDs; however, the precise structural detail of the centers in question remains to be solved. In addition, interference from background substances in complex samples such as soil, milk, blood, urine, and sewer water can also tamper the detection results. This complexity prevents CQDs from having great selectivity towards a particular analyte. The lack of understanding of the precise structure of CQDs also plagued the sensing development of CQDs. The CQDs in different separating fractions after column separation is expected to possess different specificity and affinity toward targeted analytes. Therefore, the optimal fractionated CQDs to perfectly target the analyte probably can be obtained.

For CQDs to see an increase in application, the fundamental study on the precise nature of CQDs and how to fine-tune their properties are greatly required. Careful structural analysis should substantially improve the fluorescent and electrochemical properties allowing for improved selectivity adequate for the on-field application. The improved structural understanding and synthesis methods can also improve the specificity of the CQDs-analyte interaction. However, for the sample with complex background or analytes with similar structures, pretreatment methods or additional reactions may need to be employed for purification, isolation and/or derivation of analytes to improve specificity and reduce interferences.

\section{Conclusions}

CQDs offer several advantages including high surface area, excellent solubility, superior fluorescent intensity, high resistance to photobleaching, ease tune of core and surface properties, and a variety of intermolecular interaction possible with the target analyte. This allows for a variety of detection 
strategies based on electrochemical, chemiluminescent or fluorescent detection and is a faster alternative compared to a traditional gold standard form of detection such as HPLC. While CQDs offers an excellent alternative and promising prospects, several issues still remain to detect antibiotics and pesticides. The current CQDs-based detection approach suffers from poor specificity with the target analyte. This issue can be solved with an additional purification step or modification with antibodies or aptamers. However, this highlights the problem that researches on the precise structure of CQDs is lacking and more precise synthesis and control over the structures of the CQDs are required. For CQDs to progress further and become a staple in drug analysis and biosensing, more indepth research and analysis of CQDs structure and how to synthesize different CQDs and customization of surface functional groups CQDs are highly demanded.

\section{Conflict of interest}

The authors declare no competing financial interest.

\section{Acknowledgments}

This work was supported by the Ministry of Science and Technology of Taiwan under Contract No. 107-2622-B-182-001-CC2, 107-2113-M-019-004-MY3, 107-2622-M-019-001-CC2, 107-2627-M-007-007-MY3 and 108-2638-M-002-001-MY2, and the Center of Excellence for the Oceans, National Taiwan Ocean University from The Featured Areas Research Center Program within the framework of the Higher Education Sprout Project by the Ministry of Education (MOE) in Taiwan.

\section{References}

[1] Wang X, Feng Y, Dong P, Huang J. A mini review on carbon quantum dots: preparation, properties, and electrocatalytic application. Front Chem 2019;7:671.

[2] Semeniuk M, Yi Z, Poursorkhabi V, Tjong J, Jaffer S, Lu Z-H, et al. Future perspectives and review on organic carbon dots in electronic applications. ACS Nano 2019;13:6224-55.

[3] Xia C, Zhu S, Feng T, Yang M, Yang B. Evolution and synthesis of carbon dots: from carbon dots to carbonized polymer dots. Adv Sci 2019;6:1901316.

[4] Liu ML, Chen BB, Li CM, Huang CZ. Carbon dots: synthesis, formation mechanism, fluorescence origin and sensing applications. Green Chem 2019;21:449-71.

[5] Li L, Dong T. Photoluminescence tuning in carbon dots: surface passivation or/and functionalization, heteroatom doping. J Mater Chem C 2018;6:7944-70.

[6] Zhang Z, Pan Y, Fang Y, Zhang L, Chen J, Yi C. Tuning photoluminescence and surface properties of carbon nanodots for chemical sensing. Nanoscale 2016;8:500-7.
[7] Yan F, Jiang Y, Sun X, Bai Z, Zhang Y, Zhou X. Surface modification and chemical functionalization of carbon dots: a review. Microchim Acta 2018;185:424.

[8] Wang S, Lemon Z, Cole IS, Li Q. Tailoring the edges of graphene quantum dots to establish localized $\pi-\pi$ interactions with aromatic molecules. RSC Adv 2015;5:4124854.

[9] Srivastava I, Misra SK, Bangru S, Boateng KA, Soares JANT, Schwartz-Duval AS, et al. Complementary oligonucleotide conjugated multicolor carbon dots for intracellular recognition of biological events. ACS Appl Mater Interfaces 2020;12: 16137-49.

[10] Garcia YS, Barros MR, Ventura GT, Queiroz RM, Todeschini AR, Neves JL. Probing the interaction of carbonaceous dots with transferrin and albumin: impact on the protein structure and non-synergetic metal release. J Mol Liq 2019;292:111460.

[11] Gao X, Du C, Zhuang Z, Chen W. Carbon quantum dotbased nanoprobes for metal ion detection. J Mater Chem $C$ 2016;4:6927-45.

[12] Gothwal R, Shashidhar T. Antibiotic pollution in the environment: a review. Clean 2014;43:479-89.

[13] Landers TF, Cohen B, Wittum TE, Larson EL. A review of antibiotic use in food animals: perspective, policy, and potential. Publ Health Rep 2012;127:4-22.

[14] Kraemer SA, Ramachandran AR, Perron GG. Antibiotic pollution in the environment: from microbial ecology to public policy. Microorganisms 2019;7:180.

[15] van den Dries MA, Guxens M, Pronk A, Spaan S, El Marroun H, Jusko TA, et al. Organophosphate pesticide metabolite concentrations in urine during pregnancy and offspring attention-deficit hyperactivity disorder and autistic traits. Environ Int 2019;131:105002.

[16] Bouchard MF, Bellinger DC, Wright RO, Weisskopf MG. Attention-deficit/hyperactivity disorder and urinary metabolites of organophosphate pesticides. Pediatrics 2010;125: e1270-7.

[17] Asghar U, Malik MF, Javed A. Pesticide exposure and human health: a review. J Ecosyst Ecography 2016;S5:5.

[18] Zamora-Sequeira R, Starbird-Pérez R, Rojas-Carillo O, Vargas-Villalobos $S$. What are the main sensor methods for quantifying pesticides in agricultural activities? A review. Molecules 2019;24:2659.

[19] Yan F, Sun Z, Zhang H, Sun X, Jiang Y, Bai Z. The fluorescence mechanism of carbon dots, and methods for tuning their emission color: a review. Microchim Acta 2019;186:583.

[20] Shamsipur M, Barati A, Taherpour AA, Jamshidi M. Resolving the multiple emission centers in carbon dots: from fluorophore molecular states to aromatic domain states and carbon-core states. J Phys Chem Lett 2018;9:4189-98.

[21] Park Y, Yoo J, Lim B, Kwoon W, Rhee S-W. Improving the functionality of carbon nanodots: doping and surface functionalization. J Mater Chem 2016;4:11582-603.

[22] Zu F, Yang F, Bai Z, Xiu J, Wang Y, Huang Y, et al. The quenching of the fluorescence of carbon dots: a review on mechanisms and applications. Microchim Acta 2017;184: 1899-914.

[23] Fan YZ, Zhang Y, Li N, Liu SG, Liu T, Li NB, et al. A facile synthesis of water-soluble carbon dots as a label-free fluorescent probe for rapid, selective and sensitive detection of picric acid. Sensor Actuator B 2017;240:949-55.

[24] Sun X, Lei Y. Fluorescent carbon dots and their sensing applications. Trac Trends Anal Chem 2017;89:163-80.

[25] Li M, Chen T, Gooding J, Liu J. Review of carbon and graphene quantum dots for sensing. ACS Sens 2019;4:1732-48.

[26] Abedalwafa MA, Li Y, Nia C, Wang L. Colorimetric sensor arrays for the detection and identification of antibiotics. Anal Methods 2019;11:2836-54.

[27] Pollap A, Kochana J. Electrochemical immunosensors for antibiotic detection 2019;9:61.

[28] dos Santos Fernandes GF, Nunes Salgado HR, dos Santos JL. A critical review of HPLC-based analytical methods for 
quantification of Linezolid. Crit Rev Anal Chem 2020;50: 196-211.

[29] Shi Q, Huang J, Sun Y, Deng R, Teng M, Li Q, et al. A SERSbased multiple immuno-nanoprobe for ultrasensitive detection of neomycin and quinolone antibiotics via a lateral flow assay. Microchim Acta 2018;185:84.

[30] Qiao L, Qian S, Wang Y, Yan S, Lin H. Carbon-dots-based lab-on-a-nanoparticle approach for the detection and differentiation of antibiotics. Chem Eur J 2018;24:4703-9.

[31] Fu Y, Zhao S, Wu S, Huang L, Xu T, Xing X, et al. A carbon dots-based fluorescent probe for turn-on sensing of ampicillin. Dyes Pigments 2020;172:107846.

[32] Qian S, Qiao L, Xu W, Jiang K, Wang Y, Lin H. An inner filter effect-based near-infrared probe for the ultrasensitive detection of tetracyclines and quinolones. Talanta 2019;194:598-603.

[33] Wang J, Lu T, Hu Y, Wang X, Wu Y. A label-free and carbon dots based fluorescent aptasensor for the detection of kanamycin in milk. Spectrochim Acta 2020;226:117651.

[34] Qi H, Teng M, Liu M, Liu S, Li J, Yu H, et al. Biomass-derived nitrogen-doped carbon quantum dots: highly selective fluorescent probe for detecting $\mathrm{Fe}^{3+}$ ions and tetracyclines. J Colloid Interface Sci 2019;15(539):332-41.

[35] Amjadi M, Hallaj T, Mirbirang F. A chemiluminescence reaction consisting of manganese(IV), sodium sulfite, and sulfur- and nitrogen-doped carbon quantum dots, and its application for the determination of oxytetracycline. Microchimica Acta 2020;187:191.

[36] Zhu Y, Lu Y, Shi L, Yang Y. $\beta$-Cyclodextrin functionalized $\mathrm{N}, \mathrm{Zn}$ codoped carbon dots for specific fluorescence detection of fluoroquinolones in milk samples. Microchem J 2020;153: 104517.

[37] Shi C, Qi H, Ma R, Sun Z, Xiao L, Wei G, et al. S-self-doped carbon quantum dots from fungus fibers for sensing tetracyclines and for bioimaging cancer cells. Mater Sci Eng C Mater Biol Appl 2019;105:110132.

[38] Niu J, Gao H. Synthesis and drug detection performance of nitrogen-doped carbon dots. J Lumin 2014;149:159-62.

[39] Qiao L, Qian S, Wang Y, Yan S, Lin H. Carbon-dots-based lab-on-a-nanoparticle approach for the detection and differentiation of antibiotics. Chem Eur J 2018;24:4703-9.

[40] Yang L, Zhao H, Liu N, Wang W. A target analyte induced fluorescence band shift of piperazine modified carbon quantum dots: a specific visual detection method for oxytetracycline. Chem Commun 2019;55:12364-7.

[41] Al-Hashimi B, Omer KM, Rahman HS. Inner filter effect (IFE) as a simple and selective sensing platform for detection of tetracycline using milk-based nitrogen-doped carbon nanodots as fluorescence probe. Arab J Chem 2020;13:5151-59.

[42] Xu Z, Wang Z, Liu M, Yan B, Ren X, Gao Z. Machine learning assisted dual-channel carbon quantum dots-based fluorescence sensor array for detection of tetracyclines. Spectrochim Acta 2020;232:118147.

[43] Long D, Peng J, Peng H, Xian H, Li S, Wang X, et al. A quadruple-channel fluorescent sensor array based on label-free carbon dots for sensitive detection of tetracyclines. Analyst 2019;144:3313.

[44] Li R, Hou X, Yuan M, Long Y, Chen S. Carbon dots synthesized and its applications in the detection of chlortetracycline and water based on the aggregation-induced emission. Chemistry 2020;5:649-54.

[45] Liu ML, Chen BB, Yang T, Wang J, Liu XD, Huang CZ. Onepot carbonization synthesis of europium-doped carbon quantum dots for highly selective detection of tetracycline. Methods Appl Fluoresc 2017;5:015003.

[46] Jalili R, Khataee A, Rashidi M-R, Razmjou A. Detection of penicillin $G$ residues in milk based on dual-emission carbon dots and molecularly imprinted polymers. Food Chem 2020; 314:126172.

[47] Wang K, Ji Q, Xu J, Li H, Zhang D, Liu X, et al. Highly sensitive and selective detection of amoxicillin using carbon quantum dots derived from beet. J Fluoresc 2018;28:759-65.

[48] Wang K, Shi Q, Ji Q, Li H, Zhang D, Feng H, et al. Highly sensitive and selective detection of norfloxacin in aqueous solution using carbon based nanomaterial. J Biomater Tiss Eng 2018;8:1719-24.

[49] Jayaweera S, Yin K, Ng WJ. Nitrogen-doped durian shell derived carbon dots for inner filter effect mediated sensing of tetracycline and fluorescent ink. J Fluoresc 2019;29:221-9.

[50] Guo F, Zhu Z, Zheng Z, Jin Y, Di X, Xu Z, et al. Facile synthesis of highly efficient fluorescent carbon dots for tetracycline detection. Environ Sci Pollut Res Int 2020;27:4520-7.

[51] Mandal P, Sahoo D, Sarkar P, Chakraborty K, Das S. Fluorescence turn-on and turn-off sensing of pesticides by carbon dot-based sensor. New J Chem 2019;43:12137-51.

[52] Deka MJ, Dutta P, Sarma S, Medhi OK, Talukdar NC, Chowdhury D. Carbon dots derived from water hyacinth and their application as a sensor for pretilachlor. Heliyon 2019;5:e01985.

[53] Lin B, Yan Y, Guo M, Cao Y, Yu Y, Zhang T, et al. Modification-free carbon dots as turn-on fluorescence probe for detection of organophosphorus pesticides. Food Chem 2018 245:1176-82.

[54] Wang W, Lu Y-C, Huang H, Wang A-J, Chen J-R, Feng J-J. Facile synthesis of N, S-codoped fluorescent carbon nanodots for fluorescent resonance energy transfer recognition of methotrexate with high sensitivity and selectivity. Bioscens Bioelectron 2015;64:517-22.

[55] Zhao Y, Zou S, Hou D, Hou C, Yang M, Li J, et al. Simple and sensitive fluorescence sensor for methotrexate detection based on the inner filter effect of $\mathrm{N}, \mathrm{S}$ co-doped carbon quantum dots. Anal Chim Acta 2019;1047:179-87.

[56] Kazemifard N, Ensafi AA, Rezaei B. Green synthesized carbon dots embedded in silica molecularly imprinted polymers, characterization and application as a rapid and selective fluorimetric sensor for determination of thiabendazole in juices. Food Chem 2020;310:125812.

[57] Tafreshi FA, Fatahi Z, Ghasemi SF, Taherian A, Esfandiari N. Ultrasensitive fluorescent detection of pesticides in real sample by using green carbon dots. PloS One 2020;15: e0230646.

[58] Li W-K, Feng J-T, Ma Z-Q. Nitrogen, sulfur, boron and flavonoid moiety co-incorporated carbon dots for sensitive fluorescence detection of pesticides. Carbon 2020;161: 685-93.

[59] Zor E, Morales-Narváez E, Zamora-Gálvez A, Bingol $\mathrm{H}$, Ersoz M, Merkoçi A. Graphene quantum dots-based photoluminescent sensor: a multifunctional composite for pesticide detection. ACS Appl Mater Interfaces 2015;7:20272-9.

[60] Peng J, Yin W, Shi J, Jin X, Ni G. Magnesium and nitrogen co-doped carbon dots as fluorescent probes for quenchometric determination of paraoxon using pralidoxime as a linker. Microchim Acta 2019;186:24.

[61] Luo M, Wei J, Zhao Y, Sun Y, Liang H, Wang S, et al. Fluorescent and visual detection of methyl-paraoxon by using boron-and nitrogen-doped carbon dots. Microchem J 2020;154:104547.

[62] Wei J, Yang Y, Dong J, Wang S, Li P. Fluorometric determination of pesticides and organophosphates using nanoceria as a phosphatase mimic and an inner filter effect on carbon nanodots. Microchim Acta 2019;186:66.

[63] Yang Y, Xing X, Zou T, Wang Z, Zhao R, Hong P, et al. A novel and sensitive ratiometric fluorescence assay for carbendazim based on $\mathrm{N}$-doped carbon quantum dots and gold nanocluster nanohybrid. J Hazard 2020;386:121958.

[64] Yang Y, Hou J, Hou D, Wang X, Li J, Xu G, et al. Green emitting carbon dots for sensitive fluorometric determination of cartap based on its aggregation effect on gold nanoparticles. Microchim Acta 2019;186:259.

[65] Sahub C, Tuntulani T, Nhujak T, Tomapatanaget B. Effective biosensor based on graphene quantum dots via enzymatic reaction for directly photoluminescence detection of organophosphate pesticide. Sensor Actuator B Chem 2018;258:88-97.

[66] Li H, Sun C, Vijayaraghavan R, Zhou F, Zhang X, MacFarlane DR. Long lifetime photoluminescence in N, S codoped carbon quantum dots from an ionic liquid and their 
applications in ultrasensitive detection of pesticides. Carbon 2016;104:33-9.

[67] Li H, Su D, Gao H, Yan X, Kong D, Jin R, et al. Design of red emissive carbon dots: robust performance for analytical applications in pesticide monitoring. Anal Chem 2020;92: 3198-205.

[68] Gong NC, Li YL, Jiang X, Zheng XF, Wang YY, Huan SY. Fluorescence resonance energy transfer-based biosensor composed of nitrogen-doped carbon dots and gold nanoparticles for the highly sensitive detection of organophosphorus pesticides. Anal Sci 2016;32:951-6.

[69] Wu X, Song Y, Yan X, Zhu C, Ma Y, Du D, et al. Carbon quantum dots as fluorescence resonance energy transfer sensors for organophosphate pesticides determination. Biosens Bioelectron 2017;94:292-7.

[70] Mehmood S, Khan AZ, Bilal M, Sohail A, Iqbald HMN. Aptamer-based biosensors: a novel toolkit for early diagnosis of cancer. Mater Today Chem 2019;12:353-60.

[71] Li Y, Lee J-S. Recent developments in affinity-based selection of aptamers for binding disease-related protein targets. Chem Pap 2019;73:2637-53.

[72] Tan W, Li L, Xu S, Yan H, Li X, Yazd HS, et al. Nucleic acid aptamers for molecular diagnostics and therapeutics: advances and perspectives. Angew Chem Int Ed 2020. https:// doi.org/10.1002/anie.202003563.

[73] Wu W, Yu C, Wang Q, Zhao F, He H, Liu C, et al. Research advances of DNA aptasensors for foodborne pathogen detection. Crit Rev Food Sci Nutr 2019:1-16.

[74] Saberi Z, Rezaei B, Ensafi AA. Fluorometric label-free aptasensor for detection of the pesticide acetamiprid by using cationic carbon dots prepared with cetrimonium bromide. Microchim Acta 2019;186:273.

[75] Larki A. A novel application of carbon dots for colorimetric determination of fenitrothion insecticide based on the microextraction method. Spectrochim Acta 2017;173:1-5.
[76] Siddique AB, Pramanick AK, Chatterjee S, Ray M. Amorphous carbon dots and their remarkable ability to detect 2,4,6-trinitrophenol. Sci Rep 2018;8:9770.

[77] Yen Y-T, Lin Y-S, Chen T-Y, Chyueh S-C, Chang H-T. Carbon dots functionalized papers for high-throughput sensing of 4-chloroethcathinone and its analogues in crime sites. R Soc Open Sci 2019;6:191017.

[78] Azizi B, Farhadi K, Samadi N. Functionalized carbon dots from zein biopolymer as a sensitive and selective fluorescent probe for determination of sumatriptan. Microchem J 2019; 146:965-73.

[79] Majumdar S, Bhattacharjee T, Thakur D, Chowdhury D. Carbon dot based fluorescence sensor for retinoic acid. Chemistry 2018;3:673-7.

[80] Mehta A, Mishra A, Basu S. Optical detection of thiol drugs by core-shell luminous carbon dots-gold nanoparticles system. Plasmonics 2018;13:2239-48.

[81] Han S, Fan Z, Chen X, Wu Y, Wang J. Determination of dihydralazine based on chemiluminescence resonance energy transfer of hollow carbon nanodots. Spectrochim Acta 2017;183:103-8.

[82] Luo T, Bu L, Peng S, Zhang Y, Zhou Z, Li G, et al. One-step microwave-assisted preparation of oxygen-rich multifunctional carbon quantum dots and their application for $\mathrm{Cu}^{2+}$ curcumin detection. Talanta 2019;205:120117.

[83] Han Z, Zhang H, He L, Pan S, Liu H, Hu X. One-pot hydrothermal synthesis of nitrogen and sulfur co-doped carbon dots and their application for sensitive detection of curcumin and temperature. Microchem J 2019;146:300-8.

[84] Wu B, Liu X, Shi X, Han W, Wang C, Jiang L. Highly photoluminescent and temperature-sensitive $\mathrm{P}, \mathrm{N}, \mathrm{B}$-co-doped carbon quantum dots and their highly sensitive recognition for curcumin. RSC Adv 2019;9:8340-9. 